\title{
APPENDIX II: CARBON AND CARBONATE ANALYSES, LEG 15
}

Gerald W. Bode, Scripps Institution of Oceanography, La Jolla, California

The amounts of acid soluble and acid insoluble carbon in Leg 15 sediment samples were determined using two methods of analyses: (a) the LECO 70 Second Analyzer, and (b) the LECO Acid-Base Semi Automatic Carbon Determinator. Detailed descriptions of the theory and the procedures can be found in Bader, Gerard et al. (1970) and Boyce and Bode (1972). The precision of the two methods as reported in Boyce and Bode (1972) is still valid and is discussed below for the benefit of the reader.

1) 20 Second Analyzer

Total Carbon

(1.2-12\%: $\pm 0.2 \%$ (absolute variation)

(0-1.2\%): $\pm 0.04 \%$ (absolute variation)

Organic Carbon: \pm (absolute variation)

Calcium Carbonate

(10-100\%): $\pm 2 \%$ (absolute variation)

2) Acid-Base

(0-10\%): \pm 0.6 (absolute variation)

Total Carbon

(1.2-12\%): $\pm 0.3 \%$ (absolute variation)

(0-1.2\%): $\pm 0.06 \%$ (absolute variation)

Organic Carbon: $\pm 0.06 \%$ (absolute variation)

Calcium Carbonate

(10-100\%): $\pm 3 \%$ (absolute variation)

$(0-10 \%): \pm 1 \%$ (absolute variation)

Samples analyzed using the Acid-Base method are noted with an asterisk in Table 1.

\section{REFERENCES}

Bader, R. G., Gerard, R. D. et al., 1970. Initial Reports of the Deep Sea Drilling Project, Volume IV. Washington (U. S. Government Printing Office), $745 \mathrm{p}$.

Boyce, R. E. and Bode, G. W., 1972. Carbon and carbonate analyses, Leg 9: Initial Reports of the Deep Sea Drilling Project, Volume IX. Washington (U.S. Government Printing Office), p. 797-816.

TABLE 1

Carbon-Carbonate Analyses, Leg 15

\begin{tabular}{lrrrr}
\hline $\begin{array}{c}\text { Core, Section } \\
\text { Top of } \\
\text { Interval } \\
(\mathrm{cm})\end{array}$ & $\begin{array}{c}\text { Depth } \\
\text { in Hole } \\
(\mathrm{m})\end{array}$ & $\begin{array}{c}\text { Carbon } \\
\text { Total } \\
(\%)\end{array}$ & $\begin{array}{c}\text { Organic } \\
\text { Carbon } \\
(\%)\end{array}$ & $\begin{array}{c}\mathrm{CaCO}_{3} \\
(\%)\end{array}$ \\
\hline Site 146 & & & & \\
& & & & \\
$1-3,33.00$ & 99.33 & 0.3 & $0.2^{*}$ & 1 \\
$1-6,113.00$ & 104.63 & 0.1 & $0.1^{*}$ & 0 \\
$2-1,20.00$ & 254.20 & $6.7^{*}$ & $0.2^{*}$ & 55 \\
$2-2,56.00$ & 256.06 & $6.9^{*}$ & $0.1^{*}$ & 56 \\
$2-3,72.00$ & 257.72 & $7.1^{*}$ & $0.2^{*}$ & 58 \\
$2-5,49.00$ & 260.49 & $0.5^{*}$ & 0.0 & 4 \\
$2-6,86.00$ & 262.36 & $4.5^{*}$ & 0.0 & 37 \\
& & & & \\
\hline
\end{tabular}

TABLE 1 - Continued

\begin{tabular}{|c|c|c|c|c|}
\hline $\begin{array}{l}\text { Core, Section } \\
\text { Top of } \\
\text { Interval } \\
\text { (cm) }\end{array}$ & $\begin{array}{c}\text { Depth } \\
\text { in Hole } \\
(\mathrm{m})\end{array}$ & $\begin{array}{c}\text { Carbon } \\
\text { Total } \\
(\%)\end{array}$ & $\begin{array}{c}\text { Organic } \\
\text { Carbon } \\
(\%)\end{array}$ & $\begin{array}{c}\mathrm{CaCO}_{3} \\
(\%)\end{array}$ \\
\hline $5-2.60 .00$ & 424.10 & 0.1 & $0.1^{*}$ & 0 \\
\hline $6-1,67.00$ & 431.67 & $10.9^{*}$ & $0.1^{*}$ & 90 \\
\hline $10-2,89.00$ & 469.39 & 0.0 & $0.1^{*}$ & 0 \\
\hline $\begin{array}{l}11-1,90.00 \\
11-2,27.00 \\
11-2,50.00\end{array}$ & $\begin{array}{l}476.90 \\
477.77 \\
478.00\end{array}$ & $\begin{array}{l}0.0^{*} \\
0.1^{*} \\
4.8^{*}\end{array}$ & $\begin{array}{l}0.1^{*} \\
0.1^{*} \\
0.1\end{array}$ & $\begin{array}{r}0 \\
0 \\
39\end{array}$ \\
\hline $12-1,106.00$ & 486.06 & $3.5^{*}$ & 0.1 & 29 \\
\hline $\begin{array}{l}13-1,78.00 \\
13-1,140.00 \\
13-2,105.00 \\
13-3,83.00 \\
13-4,114.00 \\
13-5,118.00\end{array}$ & $\begin{array}{l}494.78 \\
495.40 \\
496.55 \\
497.83 \\
499.64 \\
501.18\end{array}$ & $\begin{array}{l}6.1^{*} \\
4.1^{*} \\
4.0^{*} \\
5.7^{*} \\
4.1^{*} \\
3.2^{*}\end{array}$ & $\begin{array}{l}0.1 \\
0.1 \\
0.1 \\
0.1 \\
0.1 \\
0.1\end{array}$ & $\begin{array}{l}50 \\
33 \\
33 \\
47 \\
33 \\
26\end{array}$ \\
\hline $\begin{array}{l}14-1,131.00 \\
14-2,49.00 \\
14-3,82.00 \\
14-4,81.00\end{array}$ & $\begin{array}{l}504.31 \\
504.99 \\
506.82 \\
508.31\end{array}$ & $\begin{array}{l}2.4^{*} \\
3.0^{*} \\
6.3^{*} \\
7.4^{*}\end{array}$ & $\begin{array}{l}0.1 \\
0.1 \\
0.1 \\
0.1\end{array}$ & $\begin{array}{l}19 \\
24 \\
52 \\
61\end{array}$ \\
\hline $\begin{array}{l}15-1,135.00 \\
15-2,14.00 \\
15-3,41.00 \\
15-4,17.00 \\
15-5,77.00 \\
15-5,133.00 \\
15-6,97.00\end{array}$ & $\begin{array}{l}513.35 \\
513.64 \\
515.41 \\
516.67 \\
518.77 \\
519.33 \\
520.47\end{array}$ & $\begin{array}{l}5.8 \\
5.8^{*} \\
4.2^{*} \\
4.7^{*} \\
6.8^{*} \\
5.8^{*} \\
7.7^{*}\end{array}$ & $\begin{array}{l}0.0 \\
0.1 \\
0.1 \\
0.0 \\
0.0 \\
0.0 \\
0.0\end{array}$ & $\begin{array}{l}48 \\
48 \\
35 \\
38 \\
56 \\
48 \\
64\end{array}$ \\
\hline $\begin{array}{l}16-1,80.00 \\
16-2,21.00 \\
16-3,65.70 \\
16-4,139.00 \\
16-5,62.00 \\
16-6,63.00\end{array}$ & $\begin{array}{l}521.80 \\
522.71 \\
524.66 \\
526.89 \\
527.62 \\
529.13\end{array}$ & $\begin{array}{l}8.3^{*} \\
7.8^{*} \\
9.9^{*} \\
7.0^{*} \\
6.8^{*} \\
0.7^{*}\end{array}$ & $\begin{array}{l}0.1 \\
0.0 \\
0.0 \\
0.1 \\
0.0 \\
0.1\end{array}$ & $\begin{array}{r}68 \\
65 \\
82 \\
58 \\
56 \\
5\end{array}$ \\
\hline $\begin{array}{l}17-1,62.00 \\
17-2,25.00 \\
17-3,37.00 \\
17-4,56.00 \\
17-5,3.00 \\
17-6,140.00\end{array}$ & $\begin{array}{l}530.62 \\
531.75 \\
533.37 \\
535.06 \\
536.03 \\
538.90\end{array}$ & $\begin{array}{l}7.1^{*} \\
7.7^{*} \\
6.6^{*} \\
5.4^{*} \\
9.4^{*} \\
5.7^{*}\end{array}$ & $\begin{array}{l}0.0 \\
0.1 \\
0.1 \\
0.0 \\
0.0 \\
0.1\end{array}$ & $\begin{array}{l}59 \\
63 \\
54 \\
45 \\
78 \\
47\end{array}$ \\
\hline $\begin{array}{l}18-1,30.00 \\
18-2,21.00 \\
18-2,71.50 \\
18-3,38.00 \\
18-4,76.00 \\
18-5,74.00 \\
18-6,138.50\end{array}$ & $\begin{array}{l}539.30 \\
540.71 \\
541.22 \\
542.38 \\
544.26 \\
545.74 \\
547.89\end{array}$ & $\begin{array}{l}9.8^{*} \\
8.2^{*} \\
6.3^{*} \\
6.9^{*} \\
9.4^{*} \\
7.8^{*} \\
9.2^{*}\end{array}$ & $\begin{array}{l}0.1 \\
0.0 \\
0.0 \\
0.0 \\
0.0 \\
0.1 \\
0.0\end{array}$ & $\begin{array}{l}81 \\
68 \\
52 \\
57 \\
78 \\
64 \\
77\end{array}$ \\
\hline $\begin{array}{l}19-1,105.50 \\
19-2,141.00 \\
19-2,146.50 \\
19-3,76.00 \\
19-4,97.00 \\
19-7,0.00\end{array}$ & $\begin{array}{l}549.06 \\
550.91 \\
550.97 \\
551.76 \\
553.47 \\
557.00\end{array}$ & $\begin{array}{r}8.7^{*} \\
6.7^{*} \\
8.7^{*} \\
10.2^{*} \\
8.5^{*} \\
8.6^{*}\end{array}$ & $\begin{array}{l}0.0 \\
0.0 \\
0.0 \\
0.0 \\
0.0 \\
0.2 *\end{array}$ & $\begin{array}{l}72 \\
55 \\
72 \\
84 \\
70 \\
70\end{array}$ \\
\hline $\begin{array}{l}20-1,2.00 \\
20-2,84.00 \\
20-3,74.00\end{array}$ & $\begin{array}{l}557.02 \\
559.34 \\
560.74\end{array}$ & $\begin{array}{r}10.7^{*} \\
9.0^{*} \\
7.7^{*}\end{array}$ & $\begin{array}{l}0.0 \\
0.1 \\
0.0\end{array}$ & $\begin{array}{l}89 \\
75 \\
63\end{array}$ \\
\hline
\end{tabular}


TABLE 1 - Continued

\begin{tabular}{|c|c|c|c|c|}
\hline $\begin{array}{l}\text { Core, Section } \\
\text { Top of } \\
\text { Interval } \\
\text { (cm) }\end{array}$ & $\begin{array}{l}\text { Depth } \\
\text { in Hole } \\
\text { (m) }\end{array}$ & $\begin{array}{c}\text { Carbon } \\
\text { Total } \\
(\%)\end{array}$ & $\begin{array}{c}\text { Organic } \\
\text { Carbon } \\
(\%)\end{array}$ & $\begin{array}{c}\mathrm{CaCO}_{3} \\
(\%)\end{array}$ \\
\hline $\begin{array}{l}22-1,117.00 \\
22-2,89.00\end{array}$ & $\begin{array}{l}576.17 \\
577.39\end{array}$ & $\begin{array}{l}11.0^{*} \\
10.0^{*}\end{array}$ & $\begin{array}{l}0.0 \\
0.0\end{array}$ & $\begin{array}{l}91 \\
83\end{array}$ \\
\hline $\begin{array}{l}23-1,140.00 \\
23-3,87.00\end{array}$ & $\begin{array}{l}585.40 \\
587.87\end{array}$ & $\begin{array}{l}9.1^{*} \\
8.1^{*}\end{array}$ & $\begin{array}{l}0.0 \\
0.0\end{array}$ & $\begin{array}{l}76 \\
67\end{array}$ \\
\hline $24-1,11.00$ & 593.11 & $9.2^{*}$ & 0.0 & 76 \\
\hline $25-2,93.00$ & 604.43 & $7.1^{*}$ & 0.0 & 59 \\
\hline $\begin{array}{l}26-1,90.00 \\
26-2,120.00\end{array}$ & $\begin{array}{l}611.90 \\
613.70\end{array}$ & $\begin{array}{l}9.7^{*} \\
8.2^{*}\end{array}$ & $\begin{array}{l}0.0 \\
0.0\end{array}$ & $\begin{array}{l}81 \\
68\end{array}$ \\
\hline $\begin{array}{l}27-1,97.00 \\
27-2,142.00\end{array}$ & $\begin{array}{l}620.97 \\
622.92\end{array}$ & $\begin{array}{l}9.0^{*} \\
8.5^{*}\end{array}$ & $\begin{array}{l}0.0 \\
0.0\end{array}$ & $\begin{array}{l}75 \\
71\end{array}$ \\
\hline $\begin{array}{l}28-2,23.00 \\
28-2,25.00 \\
28-3,96.00\end{array}$ & $\begin{array}{l}630.73 \\
630.75 \\
632.96\end{array}$ & $\begin{array}{l}3.5^{*} \\
4.9^{*} \\
6.6^{*}\end{array}$ & $\begin{array}{l}0.0 \\
0.0 \\
0.1\end{array}$ & $\begin{array}{l}29 \\
41 \\
55\end{array}$ \\
\hline $29-1,126.00$ & 639.26 & $7.3^{*}$ & 0.0 & 61 \\
\hline $\begin{array}{l}30-1,97.00 \\
30-2,51.00 \\
30-3,0.00 \\
30-4,138.00\end{array}$ & $\begin{array}{l}647.97 \\
649.01 \\
650.00 \\
652.88\end{array}$ & $\begin{array}{l}5.2^{*} \\
6.6^{*} \\
9.0^{*} \\
6.0^{*}\end{array}$ & $\begin{array}{l}0.1 \\
0.1 \\
0.1 \\
0.0\end{array}$ & $\begin{array}{l}43 \\
55 \\
75 \\
50\end{array}$ \\
\hline $\begin{array}{l}31-1,145.00 \\
31-2,128.00 \\
31-3,124.00 \\
31-4,130.00\end{array}$ & $\begin{array}{l}657.45 \\
658.78 \\
660.24 \\
661.80\end{array}$ & $\begin{array}{r}10.1^{*} \\
10.1^{*} \\
9.7^{*} \\
6.5^{*}\end{array}$ & $\begin{array}{l}0.0 \\
0.0 \\
0.0 \\
0.1\end{array}$ & $\begin{array}{l}83 \\
84 \\
80 \\
53\end{array}$ \\
\hline $\begin{array}{l}32-1,124.00 \\
32-2,119.00\end{array}$ & $\begin{array}{l}666.24 \\
667.69\end{array}$ & $\begin{array}{l}8.9^{*} \\
7.1^{*}\end{array}$ & $\begin{array}{l}0.0 \\
0.1\end{array}$ & $\begin{array}{l}73 \\
59\end{array}$ \\
\hline $33-1,112.00$ & 675.12 & $6.9^{*}$ & 0.1 & 57 \\
\hline $\begin{array}{l}34-1,104.50 \\
34-1,105.00\end{array}$ & $\begin{array}{l}684.05 \\
684.05\end{array}$ & $\begin{array}{l}7.6^{*} \\
4.1^{*}\end{array}$ & $\begin{array}{l}0.0 \\
0.0\end{array}$ & $\begin{array}{l}63 \\
34\end{array}$ \\
\hline $35-1,134.00$ & 693.34 & $9.5^{*}$ & 0.0 & 79 \\
\hline $\begin{array}{l}36-2,83.00 \\
36-2,87.00 \\
36-2,138.00\end{array}$ & $\begin{array}{l}703.33 \\
703.37 \\
703.88\end{array}$ & $\begin{array}{r}10.2^{*} \\
8.2^{*} \\
7.7^{*}\end{array}$ & $\begin{array}{l}0.1 \\
2.5 * \\
6.3 *\end{array}$ & $\begin{array}{l}84 \\
48 \\
12\end{array}$ \\
\hline $\begin{array}{l}38-1,106.00 \\
38=1,133.00\end{array}$ & $\begin{array}{l}715.06 \\
715.33\end{array}$ & $\begin{array}{c}14.5^{*} \\
6.1\end{array}$ & $\begin{array}{c}11.1 * \\
0.3\end{array}$ & $\begin{array}{l}28 \\
49\end{array}$ \\
\hline $\begin{array}{l}39-1,71.00 \\
39-1,92.00 \\
39-2,34.00\end{array}$ & $\begin{array}{l}719.71 \\
719.92 \\
720.84\end{array}$ & $\begin{array}{l}4.1 * \\
0.2^{*} \\
9.0^{*}\end{array}$ & $\begin{array}{l}0.1 \\
0.1 * \\
0.2\end{array}$ & $\begin{array}{r}34 \\
1 \\
74\end{array}$ \\
\hline $\begin{array}{l}41-1,34.00 \\
41-2,122.00 \\
41-4,46.00\end{array}$ & $\begin{array}{l}737.34 \\
739.72 \\
741.96\end{array}$ & $\begin{array}{c}7.0^{*} \\
10.1 \\
5.3^{*}\end{array}$ & $\begin{array}{l}0.0 \\
0.0 \\
0.1\end{array}$ & $\begin{array}{l}58 \\
84 \\
44\end{array}$ \\
\hline
\end{tabular}

Site 146A

$\begin{array}{llllr}1-6,120.00 & 47.70 & 6.1^{*} & 0.1 & 50 \\ 1-7,55.00 & 48.55 & 6.3^{*} & 0.1 & 52 \\ 3-1,76.00 & 96.76 & 2.6^{*} & 0.2 & 20 \\ 3-2,40.00 & 97.90 & 0.0 & 0.1 & 0 \\ 3-3,44.00 & 99.44 & 0.0 & 0.1 & 0\end{array}$

Site 147

\begin{tabular}{lrrrr}
$2-1,126.00$ & 5.26 & 7.4 & 4.5 & 24 \\
$2-2,54.00$ & 6.04 & 6.4 & 3.4 & 25 \\
$2-3,94.00$ & 7.94 & 5.7 & 4.0 & 14 \\
$2-4,11.00$ & 8.61 & 0.6 & 0.3 & 2 \\
$2-4,30.00$ & 8.80 & 0.8 & 0.2 & 5 \\
$2-4,131.00$ & 9.81 & 3.3 & 1.6 & 15 \\
$3-1,109.00$ & 15.09 & 3.1 & 2.4 & 5 \\
$3-2,90.00$ & 16.40 & 2.4 & 1.2 & 10 \\
$3-3,123.00$ & 18.23 & 2.7 & 1.8 & 7 \\
\hline
\end{tabular}

TABLE 1 - Continued

\begin{tabular}{|c|c|c|c|c|}
\hline $\begin{array}{l}\text { Core, Section } \\
\text { Top of } \\
\text { Interval } \\
\text { (cm) }\end{array}$ & $\begin{array}{l}\text { Depth } \\
\text { in Hole } \\
(\mathrm{m})\end{array}$ & $\begin{array}{c}\text { Carbon } \\
\text { Total } \\
(\%)\end{array}$ & $\begin{array}{l}\text { Organic } \\
\text { Carbon } \\
(\%)\end{array}$ & $\begin{array}{c}\mathrm{CaCO}_{3} \\
(\%)\end{array}$ \\
\hline $\begin{array}{l}4-1,119.00 \\
4-2,12.00 \\
4-2,70.00 \\
4-2,135.00 \\
4-3,102.00 \\
4-4,69.00 \\
4-5,24.00 \\
4-5,124.00 \\
4-5,149.00 \\
4-6,4.00 \\
4-6,43.00 \\
4-6,93.00 \\
4-6,104.00 \\
4-6,115.00 \\
4-6,144.00\end{array}$ & $\begin{array}{l}24.19 \\
24.62 \\
25.20 \\
25.85 \\
27.02 \\
28.19 \\
29.24 \\
30.24 \\
30.49 \\
30.54 \\
30.93 \\
31.43 \\
31.54 \\
31.65 \\
31.94\end{array}$ & $\begin{array}{l}2.3 \\
3.4 \\
2.3 \\
3.6 \\
3.4 \\
4.3 \\
4.0 \\
5.1 \\
3.8 \\
2.9 \\
2.1 \\
2.6 \\
1.6 \\
3.1 \\
3.7\end{array}$ & $\begin{array}{l}1.4 \\
2.1 \\
1.6 \\
1.3 \\
1.4 \\
1.3 \\
2.4 \\
1.8 \\
1.7 \\
1.8 \\
0.5 \\
1.6 \\
0.6 \\
1.6 \\
1.9\end{array}$ & $\begin{array}{r}7 \\
11 \\
5 \\
20 \\
17 \\
25 \\
14 \\
28 \\
18 \\
9 \\
13 \\
8 \\
8 \\
13 \\
15\end{array}$ \\
\hline $\begin{array}{l}5-1,148.00 \\
5-2,23.00 \\
5-2,73.00 \\
5-2,102.00 \\
5-2,131.00\end{array}$ & $\begin{array}{l}33.48 \\
33.73 \\
34.23 \\
34.52 \\
34.81\end{array}$ & $\begin{array}{l}3.2 \\
2.0 \\
3.3 \\
4.0 \\
2.0\end{array}$ & $\begin{array}{l}2.1 \\
1.6 \\
2.0 \\
2.2 \\
1.2\end{array}$ & $\begin{array}{r}9 \\
3 \\
10 \\
15 \\
7\end{array}$ \\
\hline $\begin{array}{l}6-1,6.00 \\
6-3,19.00 \\
6-3,119.00 \\
6-4,14.00 \\
6-4,109.00 \\
6-5,9.00 \\
6-5,144.00 \\
6-6,67.00 \\
6-6,96.00 \\
6-6,133.00\end{array}$ & $\begin{array}{l}42.06 \\
45.19 \\
46.19 \\
46.64 \\
47.59 \\
48.09 \\
49.44 \\
50.17 \\
50.46 \\
50.83\end{array}$ & $\begin{array}{l}2.8 \\
2.5 \\
5.2 \\
5.2 \\
4.7 \\
3.5 \\
2.0 \\
3.7 \\
3.9 \\
3.3\end{array}$ & $\begin{array}{l}1.5 \\
1.7 \\
2.2 \\
2.6 \\
2.7 \\
1.5 \\
0.6 \\
0.6 \\
1.4 \\
0.5\end{array}$ & $\begin{array}{r}11 \\
7 \\
24 \\
21 \\
17 \\
17 \\
12 \\
26 \\
21 \\
23\end{array}$ \\
\hline $\begin{array}{l}7-1,56.00 \\
7-2,7.00 \\
7-2,24.00 \\
7-2,39.00 \\
7-2,135.00\end{array}$ & $\begin{array}{l}51.56 \\
52.57 \\
52.74 \\
52.89 \\
53.85\end{array}$ & $\begin{array}{l}5.3 \\
3.5 \\
4.4 \\
5.6 \\
3.2\end{array}$ & $\begin{array}{l}2.5 \\
1.5 \\
2.4 \\
2.2 \\
0.9\end{array}$ & $\begin{array}{l}23 \\
16 \\
17 \\
28 \\
19\end{array}$ \\
\hline $\begin{array}{l}8-2,29.00 \\
8-2,136.00 \\
8-3,19.00 \\
8-3,132.00 \\
8-4,135.00 \\
8-5,84.00 \\
8-5,140.00 \\
8-6,98.00 \\
8-7,99.00 \\
8-7,0.00\end{array}$ & $\begin{array}{l}61.79 \\
62.86 \\
63.19 \\
64.32 \\
65.85 \\
66.84 \\
67.40 \\
68.48 \\
69.99 \\
69.00\end{array}$ & $\begin{array}{l}3.0 \\
3.6 \\
2.0 \\
3.9 \\
3.8 \\
2.3 \\
4.8 \\
5.8 \\
5.4 \\
2.6\end{array}$ & $\begin{array}{l}1.5 \\
1.6 \\
0.6 \\
2.0 \\
2.2 \\
0.6 \\
1.6 \\
2.4 \\
2.2 \\
0.9\end{array}$ & $\begin{array}{l}12 \\
16 \\
11 \\
16 \\
13 \\
14 \\
27 \\
28 \\
27 \\
14\end{array}$ \\
\hline $\begin{array}{l}9-2,27.00 \\
9-2,129.00 \\
9-3,29.00 \\
9-4,79.00 \\
9-4,139.00 \\
9-5,109.00 \\
9-6,39.00 \\
9-6,139.00\end{array}$ & $\begin{array}{l}70.77 \\
71.79 \\
72.29 \\
74.29 \\
74.89 \\
76.09 \\
76.89 \\
77.89\end{array}$ & $\begin{array}{l}2.6 \\
6.3 \\
6.9 \\
5.7 \\
5.9 \\
4.4 \\
4.2 \\
4.9\end{array}$ & $\begin{array}{l}0.8 \\
2.8 \\
3.3 \\
1.4 \\
1.3 \\
1.9 \\
1.6 \\
1.1\end{array}$ & $\begin{array}{l}15 \\
30 \\
30 \\
36 \\
38 \\
21 \\
21 \\
31\end{array}$ \\
\hline $\begin{array}{l}10-1,8.00 \\
10-2,130.00 \\
10-3,123.00 \\
10-4,44.00 \\
10-4,94.00 \\
10-5,0.00 \\
10-5,32.00 \\
10-5,52.00\end{array}$ & $\begin{array}{l}78.08 \\
80.80 \\
82.23 \\
82.94 \\
83.44 \\
84.00 \\
84.32 \\
84.52\end{array}$ & $\begin{array}{l}4.7 \\
2.7 \\
5.0 \\
5.2 \\
4.8 \\
6.6 \\
8.2 \\
4.1\end{array}$ & $\begin{array}{l}1.7 \\
0.8 \\
1.9 \\
2.5 \\
1.3 \\
1.8 \\
0.5 \\
0.5\end{array}$ & $\begin{array}{l}25 \\
15 \\
26 \\
22 \\
29 \\
40 \\
64 \\
30\end{array}$ \\
\hline $\begin{array}{l}11-1,30.00 \\
11-1,141.00 \\
11-2,12.00\end{array}$ & $\begin{array}{l}88.30 \\
89.41 \\
89.62\end{array}$ & $\begin{array}{l}5.3 \\
5.2 \\
5.1\end{array}$ & $\begin{array}{l}0.6 \\
0.9 \\
1.0\end{array}$ & $\begin{array}{l}39 \\
36 \\
34\end{array}$ \\
\hline
\end{tabular}


TABLE 1 - Continued

\begin{tabular}{|c|c|c|c|c|}
\hline $\begin{array}{l}\text { Core, Section } \\
\text { Top of } \\
\text { Interval } \\
\text { (cm) }\end{array}$ & $\begin{array}{l}\text { Depth } \\
\text { in Hole } \\
(\mathrm{m})\end{array}$ & $\begin{array}{c}\text { Carbon } \\
\text { Total } \\
(\%)\end{array}$ & $\begin{array}{c}\text { Organic } \\
\text { Carbon } \\
(\%)\end{array}$ & $\begin{array}{c}\mathrm{CaCO}_{3} \\
(\%)\end{array}$ \\
\hline $\begin{array}{l}11-3,81.00 \\
11-4,67.00 \\
11-5,30.00 \\
11-6,37.00 \\
11-7,46.00\end{array}$ & $\begin{array}{l}91.81 \\
93.17 \\
94.30 \\
95.87 \\
97.46\end{array}$ & $\begin{array}{l}5.9 \\
6.6 \\
6.5 \\
6.5 \\
6.6\end{array}$ & $\begin{array}{l}1.9 \\
1.9 \\
2.0 \\
2.3 \\
1.6\end{array}$ & $\begin{array}{l}33 \\
39 \\
37 \\
35 \\
41\end{array}$ \\
\hline $\begin{array}{l}12-1,66.00 \\
12-2,19.00 \\
12-3,107.00 \\
12-4,50.00 \\
12-4,73.00 \\
12-4,145.00 \\
12-5,16.00 \\
12-5,43.00 \\
12-5,99.00 \\
12-5,143.00 \\
12-6,37.00\end{array}$ & $\begin{array}{r}97.66 \\
98.69 \\
101.07 \\
102.00 \\
102.23 \\
102.95 \\
103.16 \\
103.43 \\
103.99 \\
104.43 \\
104.87\end{array}$ & $\begin{array}{l}6.6 \\
6.2 \\
5.7 \\
2.2 \\
1.1 \\
1.3 \\
7.4 \\
4.0 \\
3.0 \\
3.7 \\
2.7\end{array}$ & $\begin{array}{l}1.8 \\
1.7 \\
1.3 \\
0.6 \\
0.2 \\
0.2 \\
0.9 \\
1.9 \\
0.4 \\
0.6 \\
0.5\end{array}$ & $\begin{array}{r}40 \\
37 \\
36 \\
13 \\
7 \\
10 \\
54 \\
18 \\
21 \\
25 \\
19\end{array}$ \\
\hline $\begin{array}{l}13-1,5.00 \\
13-1,50.00 \\
13-2,60.00 \\
13-3,28.00 \\
13-3,124.00 \\
13-4,38.00 \\
13-5,92.00 \\
13-6,71.00\end{array}$ & $\begin{array}{l}106.05 \\
106.50 \\
108.10 \\
109.28 \\
110.24 \\
110.88 \\
112.92 \\
114.21\end{array}$ & $\begin{array}{l}4.1 \\
3.6 \\
4.3 \\
6.1 \\
3.9 \\
4.1 \\
4.6 \\
4.5\end{array}$ & $\begin{array}{l}1.0 \\
1.3 \\
1.5 \\
1.7 \\
1.5 \\
1.5 \\
1.7 \\
1.8\end{array}$ & $\begin{array}{l}26 \\
18 \\
23 \\
37 \\
20 \\
22 \\
24 \\
23\end{array}$ \\
\hline $\begin{array}{l}14-2,29.00 \\
14-3,92.00 \\
14-3,119.00 \\
14-3,134.00 \\
14-4,14.00 \\
14-5,75.00\end{array}$ & $\begin{array}{l}116.79 \\
118.92 \\
119.19 \\
119.34 \\
119.64 \\
121.75\end{array}$ & $\begin{array}{l}3.6 \\
5.7 \\
1.7 \\
4.7 \\
4.1 \\
5.5\end{array}$ & $\begin{array}{l}1.2 \\
2.5 \\
0.8 \\
1.8 \\
1.3 \\
1.7\end{array}$ & $\begin{array}{r}20 \\
27 \\
7 \\
24 \\
23 \\
32\end{array}$ \\
\hline $\begin{array}{l}15-1,22.00 \\
15-2,50.00 \\
15-3,28.00 \\
15-4,99.00 \\
15-5,29.00 \\
15-6,7.00\end{array}$ & $\begin{array}{l}124.22 \\
126.00 \\
127.28 \\
129.49 \\
130.29 \\
131.57\end{array}$ & $\begin{array}{l}5.4 \\
2.5 \\
3.6 \\
3.4 \\
3.5 \\
4.0\end{array}$ & $\begin{array}{l}1.2 \\
1.0 \\
1.2 \\
1.1 \\
1.2 \\
1.5\end{array}$ & $\begin{array}{l}34 \\
12 \\
20 \\
19 \\
19 \\
20\end{array}$ \\
\hline $\begin{array}{l}16-1,134.00 \\
16-2,125.00 \\
16-3,89.00 \\
16-4,71.00\end{array}$ & $\begin{array}{l}135.34 \\
136.75 \\
137.89 \\
139.21\end{array}$ & $\begin{array}{l}3.8 \\
4.1 \\
5.7 \\
3.6\end{array}$ & $\begin{array}{l}2.0 \\
1.9 \\
2.7 \\
2.0\end{array}$ & $\begin{array}{l}15 \\
18 \\
24 \\
13\end{array}$ \\
\hline $\begin{array}{l}17-1,5.00 \\
17-1,107.00 \\
17-2,50.00 \\
17-3,45.00 \\
17-4,21.00 \\
17-5,143.00 \\
17-6,14.00\end{array}$ & $\begin{array}{l}144.05 \\
145.07 \\
146.00 \\
147.45 \\
148.71 \\
151.43 \\
151.64\end{array}$ & $\begin{array}{l}6.2 \\
6.6 \\
6.5 \\
6.2 \\
6.0 \\
5.6 \\
6.5\end{array}$ & $\begin{array}{l}3.0 \\
2.9 \\
3.1 \\
3.2 \\
2.9 \\
2.6 \\
3.1\end{array}$ & $\begin{array}{l}27 \\
31 \\
29 \\
25 \\
26 \\
25 \\
28\end{array}$ \\
\hline $\begin{array}{l}18-1,48.00 \\
18-2,42.00 \\
18-3,51.00 \\
18-4,74.00 \\
18-5,42.00 \\
18-6,43.00 \\
18-6,91.00 \\
18-6,143.00\end{array}$ & $\begin{array}{l}153.48 \\
154.92 \\
156.51 \\
158.24 \\
159.42 \\
160.93 \\
161.41 \\
161.93\end{array}$ & $\begin{array}{l}5.2 \\
5.5 \\
3.9 \\
3.7 \\
3.9 \\
4.2 \\
3.3 \\
5.1\end{array}$ & $\begin{array}{l}2.9 \\
3.2 \\
1.6 \\
2.0 \\
1.8 \\
2.6 \\
1.7 \\
2.5\end{array}$ & $\begin{array}{l}20 \\
19 \\
19 \\
14 \\
17 \\
13 \\
13 \\
22\end{array}$ \\
\hline \multicolumn{5}{|l|}{ Site 147C } \\
\hline $\begin{array}{l}7-2,137.00 \\
7-3,48.00 \\
7-5,74.00 \\
7-6,144.00\end{array}$ & $\begin{array}{l}172.87 \\
173.48 \\
176.74 \\
178.94\end{array}$ & $\begin{array}{l}3.8 \\
4.3 \\
3.8 \\
4.2\end{array}$ & $\begin{array}{l}2.3 \\
2.4 \\
2.3 \\
2.1\end{array}$ & $\begin{array}{l}12 \\
16 \\
13 \\
17\end{array}$ \\
\hline
\end{tabular}

TABLE 1 - Continued

\begin{tabular}{|c|c|c|c|c|}
\hline $\begin{array}{l}\text { Core, Section } \\
\text { Top of } \\
\text { Interval } \\
(\mathrm{cm})\end{array}$ & $\begin{array}{l}\text { Depth } \\
\text { in Hole } \\
\text { (m) }\end{array}$ & $\begin{array}{c}\text { Carbon } \\
\text { Total } \\
(\%)\end{array}$ & $\begin{array}{c}\text { Organic } \\
\text { Carbon } \\
(\%)\end{array}$ & $\begin{array}{c}\mathrm{CaCO}_{3} \\
(\%)\end{array}$ \\
\hline \multicolumn{5}{|l|}{ Site 148} \\
\hline $\begin{array}{l}1-2,40.00 \\
1-2,46.00 \\
1-3,69.00 \\
1-5,14.00\end{array}$ & $\begin{array}{l}1.90 \\
1.96 \\
3.69 \\
6.14\end{array}$ & $\begin{array}{l}4.3 \\
5.9 \\
3.3 \\
2.2\end{array}$ & $\begin{array}{l}0.4 \\
0.1 \\
0.4 \\
0.3\end{array}$ & $\begin{array}{l}33 \\
48 \\
24 \\
16\end{array}$ \\
\hline $\begin{array}{l}2-1,109.00 \\
2-2,24.00 \\
2-2,91.00 \\
2-3,39.00 \\
2-5,43.00\end{array}$ & $\begin{array}{l}10.09 \\
10.74 \\
11.41 \\
12.39 \\
15.43\end{array}$ & $\begin{array}{l}4.6 \\
4.2 \\
6.2 \\
2.9 \\
3.2\end{array}$ & $\begin{array}{l}0.1 \\
0.4 \\
0.1 \\
0.4 \\
0.5\end{array}$ & $\begin{array}{l}37 \\
32 \\
50 \\
20 \\
23\end{array}$ \\
\hline $\begin{array}{l}3-1,135.00 \\
3-2,17.00 \\
3-2,137.00 \\
3-3,25.00 \\
3-4,45.00\end{array}$ & $\begin{array}{l}19.35 \\
19.67 \\
20.87 \\
21.25 \\
22.95\end{array}$ & $\begin{array}{l}2.9 \\
1.9 \\
3.2 \\
1.3 \\
1.6\end{array}$ & $\begin{array}{l}0.4 \\
0.5 \\
0.4 \\
0.3 \\
0.3\end{array}$ & $\begin{array}{r}21 \\
12 \\
24 \\
9 \\
10\end{array}$ \\
\hline $\begin{array}{l}4-1,135.00 \\
42,44.00 \\
4-3,4.00 \\
4-4,126.00 \\
4-5,26.00 \\
4-5,116.00\end{array}$ & $\begin{array}{l}28.35 \\
28.94 \\
30.04 \\
32.76 \\
33.26 \\
34.16\end{array}$ & $\begin{array}{l}2.6 \\
2.8 \\
2.3 \\
1.5 \\
2.9 \\
3.0\end{array}$ & $\begin{array}{l}0.3 \\
0.4 \\
0.4 \\
0.4 \\
0.3 \\
0.4\end{array}$ & $\begin{array}{l}19 \\
20 \\
16 \\
10 \\
21 \\
22\end{array}$ \\
\hline $\begin{array}{l}5-1,80.00 \\
5-2,80.00 \\
5-3,30.00 \\
5-3,129.00\end{array}$ & $\begin{array}{l}36.80 \\
38.30 \\
39.30 \\
40.29\end{array}$ & $\begin{array}{l}2.8 \\
5.2 \\
4.9 \\
1.4\end{array}$ & $\begin{array}{l}0.4 \\
0.2 \\
0.3 \\
0.4\end{array}$ & $\begin{array}{l}20 \\
42 \\
38 \\
8\end{array}$ \\
\hline $\begin{array}{l}6-1,89.00 \\
6-2,69.00 \\
6-3,20.00 \\
6-5,36.00 \\
6-6,10.00\end{array}$ & $\begin{array}{l}45.89 \\
47.19 \\
48.20 \\
51.36 \\
52.60\end{array}$ & $\begin{array}{l}2.4 \\
1.5 \\
3.5 \\
3.6 \\
2.3\end{array}$ & $\begin{array}{l}0.4 \\
0.2 \\
0.4 \\
0.4 \\
0.3\end{array}$ & $\begin{array}{l}16 \\
11 \\
26 \\
27 \\
17\end{array}$ \\
\hline $\begin{array}{l}7-1,117.00 \\
7-1,142.00 \\
7-2,74.00 \\
7-3,74.00 \\
7-4,32.00 \\
7-4,125.00\end{array}$ & $\begin{array}{l}56.17 \\
56.42 \\
57.24 \\
58.74 \\
59.82 \\
60.75\end{array}$ & $\begin{array}{l}2.6 \\
2.1 \\
1.5 \\
1.2 \\
1.5 \\
2.4\end{array}$ & $\begin{array}{l}0.3 \\
0.3 \\
0.4 \\
0.4 \\
0.4 \\
0.3\end{array}$ & $\begin{array}{r}19 \\
14 \\
9 \\
6 \\
9 \\
18\end{array}$ \\
\hline $\begin{array}{l}8-1,42.00 \\
8-2,67.00 \\
8-2,82.00 \\
8-3,77.00 \\
8-3,143.00 \\
8-4,21.00 \\
8-4,59.00\end{array}$ & $\begin{array}{l}64.42 \\
66.17 \\
66.32 \\
67.77 \\
68.43 \\
68.71 \\
69.09\end{array}$ & $\begin{array}{l}1.5 \\
1.3 \\
2.7 \\
1.1 \\
1.2 \\
3.3 \\
1.2\end{array}$ & $\begin{array}{l}0.4 \\
0.4 \\
0.5 \\
0.4 \\
0.5 \\
0.5 \\
0.5\end{array}$ & $\begin{array}{r}9 \\
7 \\
19 \\
6 \\
6 \\
23 \\
5\end{array}$ \\
\hline $\begin{array}{l}9-1,110.00 \\
9-2,13.00 \\
9-3,27.00 \\
9-4,20.00 \\
9-5,14.00\end{array}$ & $\begin{array}{l}74.10 \\
74.63 \\
76.27 \\
77.70 \\
79.14\end{array}$ & $\begin{array}{l}1.1 \\
2.7 \\
2.4 \\
1.6 \\
2.7\end{array}$ & $\begin{array}{l}0.5 \\
0.4 \\
0.6 \\
0.6 \\
0.5\end{array}$ & $\begin{array}{r}5 \\
19 \\
15 \\
8 \\
19\end{array}$ \\
\hline $\begin{array}{l}10-1,23.00 \\
10-1,40.00 \\
10-2,45.00 \\
10-2,124.00 \\
10-3,65.00 \\
10-4,107.00\end{array}$ & $\begin{array}{l}82.23 \\
82.40 \\
83.95 \\
84.74 \\
85.65 \\
87.57\end{array}$ & $\begin{array}{l}1.6 \\
1.4 \\
1.2 \\
2.9 \\
1.3 \\
0.9\end{array}$ & $\begin{array}{l}0.4 \\
0.5 \\
0.7 \\
1.3 \\
0.4 \\
0.3\end{array}$ & $\begin{array}{r}10 \\
7 \\
4 \\
14 \\
7 \\
5\end{array}$ \\
\hline $\begin{array}{l}11-1,141.00 \\
11-1,43.00 \\
11-2,51.00 \\
11-3,88.00 \\
11-4,37.00 \\
11-5,114.00 \\
11-6,68.00\end{array}$ & $\begin{array}{l}92.41 \\
91.43 \\
93.01 \\
94.88 \\
95.87 \\
98.14 \\
99.18\end{array}$ & $\begin{array}{l}1.6 \\
1.6 \\
1.2 \\
1.4 \\
1.4 \\
1.6 \\
2.5\end{array}$ & $\begin{array}{l}0.5 \\
0.9 \\
0.5 \\
0.0 \\
0.5 \\
0.0 \\
0.7\end{array}$ & $\begin{array}{r}9 \\
6 \\
5 \\
11 \\
7 \\
13 \\
15\end{array}$ \\
\hline
\end{tabular}


TABLE 1 - Continued

\begin{tabular}{|c|c|c|c|c|}
\hline $\begin{array}{l}\text { Core, Section } \\
\text { Top of } \\
\text { Interval } \\
\text { (cm) }\end{array}$ & $\begin{array}{l}\text { Depth } \\
\text { in Hole } \\
\text { (m) }\end{array}$ & $\begin{array}{c}\text { Carbon } \\
\text { Total } \\
(\%)\end{array}$ & $\begin{array}{c}\text { Organic } \\
\text { Carbon } \\
(\%)\end{array}$ & $\begin{array}{c}\mathrm{CaCO}_{3} \\
(\%)\end{array}$ \\
\hline $\begin{array}{l}12-1,68.00 \\
12-1,140.00 \\
12-2,143.00 \\
12-3,72.00 \\
12-5,30.00 \\
12-6,49.00\end{array}$ & $\begin{array}{l}100.68 \\
101.40 \\
102.93 \\
103.72 \\
106.30 \\
107.99\end{array}$ & $\begin{array}{l}3.5 \\
3.1 \\
2.4 \\
2.1 \\
1.4 \\
1.8\end{array}$ & $\begin{array}{l}0.6 \\
0.6 \\
0.7 \\
0.7 \\
0.6 \\
0.6\end{array}$ & $\begin{array}{r}24 \\
21 \\
14 \\
12 \\
7 \\
9\end{array}$ \\
\hline $\begin{array}{l}13-1,143.00 \\
13-2,145.00 \\
13-3,120.00 \\
13-4,120.00 \\
13-5,106.00 \\
13-6,44.00 \\
13-6,138.00\end{array}$ & $\begin{array}{l}110.43 \\
111.95 \\
113.20 \\
114.70 \\
116.06 \\
116.94 \\
117.88\end{array}$ & $\begin{array}{l}1.3 \\
2.2 \\
1.7 \\
1.4 \\
1.6 \\
2.9 \\
2.4\end{array}$ & $\begin{array}{l}0.6 \\
0.7 \\
0.7 \\
0.6 \\
0.6 \\
0.7 \\
0.5\end{array}$ & $\begin{array}{r}6 \\
13 \\
8 \\
8 \\
6 \\
8 \\
19 \\
16\end{array}$ \\
\hline $\begin{array}{l}14-1,120.00 \\
14-2,20.00 \\
14-3,74.00 \\
14-4,116.00\end{array}$ & $\begin{array}{l}119.20 \\
119.70 \\
121.74 \\
123.66\end{array}$ & $\begin{array}{l}1.9 \\
1.7 \\
1.3 \\
2.0\end{array}$ & $\begin{array}{l}0.7 \\
0.6 \\
0.6 \\
0.6\end{array}$ & $\begin{array}{r}10 \\
9 \\
5 \\
11\end{array}$ \\
\hline $\begin{array}{l}15-1,142.00 \\
15-2,110.00 \\
15-3,74.00 \\
15-4,135.00 \\
15-5,110.00 \\
15-5,135.00 \\
15-6,80.00\end{array}$ & $\begin{array}{l}128.42 \\
129.60 \\
130.74 \\
132.85 \\
134.10 \\
134.35 \\
135.30\end{array}$ & $\begin{array}{l}3.3 \\
1.2 \\
1.8 \\
2.0 \\
2.0 \\
1.2 \\
2.3\end{array}$ & $\begin{array}{l}0.6 \\
0.5 \\
0.6 \\
0.6 \\
0.6 \\
0.6 \\
0.5\end{array}$ & $\begin{array}{r}23 \\
6 \\
9 \\
9 \\
12 \\
11 \\
5 \\
15\end{array}$ \\
\hline $\begin{array}{l}16-1,140.00 \\
16-2,100.00 \\
16-3,18.00 \\
16-4,33.00 \\
16-4,132.00\end{array}$ & $\begin{array}{l}138.40 \\
139.50 \\
140.18 \\
141.83 \\
142.82\end{array}$ & $\begin{array}{l}2.8 \\
1.8 \\
2.7 \\
2.2 \\
1.2\end{array}$ & $\begin{array}{l}0.5 \\
0.4 \\
0.5 \\
0.5 \\
0.4\end{array}$ & $\begin{array}{r}19 \\
11 \\
18 \\
15 \\
7\end{array}$ \\
\hline $\begin{array}{l}17-1,75.00 \\
17-2,109.00 \\
17-3,79.00 \\
17-4,97.00 \\
17-5,57.00 \\
17-5,92.00 \\
17-6,90.00\end{array}$ & $\begin{array}{l}146.75 \\
148.59 \\
149.79 \\
151.47 \\
152.57 \\
152.92 \\
154.40\end{array}$ & $\begin{array}{l}0.9 \\
1.9 \\
2.3 \\
1.2 \\
6.2 \\
1.9 \\
1.7\end{array}$ & $\begin{array}{l}0.4 \\
0.7 \\
0.4 \\
0.4 \\
2.4 \\
0.3 \\
0.5\end{array}$ & $\begin{array}{r}4 \\
10 \\
15 \\
7 \\
31 \\
13 \\
10\end{array}$ \\
\hline $\begin{array}{l}18-1,75.00 \\
18-2,14.00\end{array}$ & $\begin{array}{l}156.75 \\
157.64\end{array}$ & $\begin{array}{l}1.4 \\
1.5\end{array}$ & $\begin{array}{l}0.4 \\
0.4\end{array}$ & $\begin{array}{l}8 \\
9\end{array}$ \\
\hline $\begin{array}{l}19-1,58.00 \\
19-2,98.00 \\
19-2,100.00\end{array}$ & $\begin{array}{l}165.58 \\
167.48 \\
167.50\end{array}$ & $\begin{array}{l}1.2 \\
2.1 \\
1.9\end{array}$ & $\begin{array}{l}0.4 \\
0.5 \\
0.5\end{array}$ & $\begin{array}{r}6 \\
14 \\
12\end{array}$ \\
\hline $\begin{array}{l}20-1,74.00 \\
20-2,8.00 \\
20-3,74.00 \\
20-4,41.00 \\
20-5,135.00 \\
20-6,102.00\end{array}$ & $\begin{array}{l}175.74 \\
176.58 \\
178.74 \\
179.91 \\
182.35 \\
183.52\end{array}$ & $\begin{array}{l}2.0 \\
2.0 \\
2.3 \\
1.2 \\
1.7 \\
1.6\end{array}$ & $\begin{array}{l}0.0 \\
0.5 \\
0.6 \\
0.5 \\
0.5 \\
0.4\end{array}$ & $\begin{array}{r}17 \\
13 \\
15 \\
6 \\
11 \\
11\end{array}$ \\
\hline $\begin{array}{l}21-1,135.00 \\
21-2,74.00 \\
21-3,84.00\end{array}$ & $\begin{array}{l}185.35 \\
186.24 \\
187.84\end{array}$ & $\begin{array}{l}1.5 \\
2.0 \\
1.8\end{array}$ & $\begin{array}{l}0.4 \\
0.6 \\
0.5\end{array}$ & $\begin{array}{r}9 \\
12 \\
11\end{array}$ \\
\hline $\begin{array}{l}22-1,59.00 \\
22-2,74.00 \\
22-3,20.00\end{array}$ & $\begin{array}{l}193.59 \\
195.24 \\
196.20\end{array}$ & $\begin{array}{l}1.6 \\
2.3 \\
2.7\end{array}$ & $\begin{array}{l}0.6 \\
0.5 \\
0.6\end{array}$ & $\begin{array}{r}8 \\
15 \\
17\end{array}$ \\
\hline $\begin{array}{l}23-1,14.00 \\
23-1,89.00 \\
23-2,107.00 \\
23-3,36.00 \\
23-4,30.00 \\
23-5,15.00 \\
23-6,136.00\end{array}$ & $\begin{array}{l}203.14 \\
203.89 \\
205.57 \\
206.36 \\
207.80 \\
209.15 \\
211.86\end{array}$ & $\begin{array}{l}2.2 \\
2.2 \\
1.9 \\
1.6 \\
2.5 \\
1.8 \\
2.4\end{array}$ & $\begin{array}{l}0.5 \\
0.5 \\
0.6 \\
0.4 \\
0.5 \\
0.5 \\
0.7\end{array}$ & $\begin{array}{l}15 \\
14 \\
11 \\
10 \\
16 \\
11 \\
14\end{array}$ \\
\hline $\begin{array}{l}24-1,119.00 \\
24-2,109.00\end{array}$ & $\begin{array}{l}213.19 \\
214.59\end{array}$ & $\begin{array}{l}1.9 \\
2.2\end{array}$ & $\begin{array}{l}0.5 \\
0.4\end{array}$ & $\begin{array}{l}11 \\
15\end{array}$ \\
\hline
\end{tabular}

TABLE 1 - Continued

\begin{tabular}{lcccc}
\hline $\begin{array}{c}\text { Core, Section } \\
\text { Top of } \\
\text { Interval } \\
(\mathrm{cm})\end{array}$ & $\begin{array}{c}\text { Depth } \\
\text { in Hole } \\
(\mathrm{m})\end{array}$ & $\begin{array}{c}\text { Carbon } \\
\text { Total } \\
(\%)\end{array}$ & $\begin{array}{c}\text { Organic } \\
\text { Carbon } \\
(\%)\end{array}$ & $\begin{array}{c}\mathrm{CaCO}_{3} \\
(\%)\end{array}$ \\
\hline $24-3,65.00$ & 215.65 & 2.1 & 0.6 & 13 \\
$24-4,73.00$ & 217.23 & 2.4 & 0.5 & 16 \\
$24-5,15.00$ & 218.15 & 2.8 & 0.5 & 19 \\
$24-6,19.00$ & 219.69 & 2.9 & 0.6 & 19 \\
$25-1,112.00$ & 222.12 & 2.9 & 0.5 & 20 \\
$25-2,46.00$ & 222.96 & 3.1 & 0.4 & 22 \\
$26-1,148.00$ & 231.48 & 1.7 & 0.4 & 11 \\
$26-2,74.00$ & 232.24 & 2.7 & 0.4 & 19 \\
$27-1,132.00$ & 241.32 & 3.7 & 0.3 & 28 \\
$27-1,143.00$ & 241.43 & 3.6 & 0.4 & 27 \\
$27-2,40.00$ & 241.90 & 4.1 & 0.4 & 31 \\
$27-3,14.00$ & 243.14 & 3.1 & 0.4 & 23 \\
$27-4,14.00$ & 244.64 & 3.0 & 0.4 & 22 \\
$27-5,75.00$ & 246.75 & 4.4 & 0.4 & 34 \\
$27-6,14.00$ & 247.64 & 3.8 & 0.4 & 28 \\
$31-1,126.00$ & 268.26 & 0.9 & 0.6 & 3 \\
$31-2,110.00$ & 269.60 & 1.0 & 0.6 & 3
\end{tabular}

Site 149

\begin{tabular}{lrlll}
$2-1,62.00$ & 1.62 & 6.9 & 0.1 & 57 \\
$2-3,14.00$ & 4.14 & 7.7 & 0.1 & 63 \\
$2-3,51.00$ & 4.51 & 3.0 & 0.1 & 24 \\
$2-3,68.00$ & 4.68 & 6.5 & 0.1 & 53 \\
$2-3,134.00$ & 5.34 & 7.1 & 0.2 & 58 \\
$2-4,15.00$ & 5.65 & 6.9 & 0.1 & 56 \\
$2-4,107.00$ & 6.57 & 6.5 & 0.1 & 53 \\
$2-5,59.00$ & 7.59 & 7.7 & 0.1 & 64 \\
$2-6,14.00$ & 8.64 & 8.8 & 0.1 & 72 \\
$2-6,112.00$ & 9.62 & 7.9 & 0.1 & 65 \\
$3-1,112.00$ & 11.12 & 7.9 & 0.1 & 65 \\
$3-2,20.00$ & 11.70 & 6.1 & 0.1 & 50 \\
$3-3,91.00$ & 13.91 & 6.2 & 0.1 & 51 \\
$3-4,103.00$ & 15.53 & 8.3 & 0.1 & 69 \\
$3-5,15.00$ & 16.15 & 6.0 & 0.5 & 46 \\
$3-6,14.00$ & 17.64 & 6.5 & 0.1 & 53 \\
$3-6,94.00$ & 18.44 & 5.1 & 0.1 & 42 \\
$3-6,103.00$ & 18.53 & 6.7 & 0.1 & 55 \\
$4-1,65.00$ & 19.65 & 6.4 & 0.1 & 52 \\
$4-2,42.00$ & 20.92 & 6.9 & 0.3 & 54 \\
$4-2,110.00$ & 21.60 & 7.1 & 0.1 & 58 \\
$4-3,11.00$ & 22.11 & 4.2 & 0.1 & 35 \\
$4-4,3.00$ & 23.53 & 4.6 & 0.1 & 37 \\
$4-4,75.00$ & 24.25 & 7.3 & 0.1 & 60 \\
$4-5,44.00$ & 25.44 & 4.3 & 0.1 & 35 \\
$4-5,138.00$ & 26.38 & 5.3 & 0.3 & 41 \\
$5-1,82.00$ & 28.82 & 5.5 & 0.1 & 45 \\
$5-1,130.00$ & 29.30 & 6.6 & 0.1 & 54 \\
$5-2,27.00$ & 29.77 & 4.1 & 0.1 & 33 \\
$5-2,133.00$ & 30.83 & 5.3 & 0.1 & 43 \\
$5-3,31.00$ & 31.31 & 4.7 & 0.2 & 38 \\
$5-3,103.00$ & 32.03 & 4.5 & 0.2 & 36 \\
$5-4,75.00$ & 33.25 & 75 & 0.1 & 62 \\
$5-4,109.00$ & 33.59 & 0.4 & 0.2 & 2 \\
$5-5,75.00$ & 34.75 & 4.9 & 0.2 & 39 \\
$6-1,26.00$ & 37.26 & 6.4 & 0.1 & 52 \\
$6-2,7.00$ & 38.57 & 4.5 & 0.1 & 37 \\
$6-2,74.00$ & 39.24 & 6.0 & 0.1 & 49 \\
$6-2,107.50$ & 39.58 & 5.3 & 0.2 & 43 \\
$6-3,12.00$ & 40.12 & 4.9 & 0.2 & 40 \\
$6-4,32.00$ & 41.82 & 5.3 & 0.2 & 43 \\
$6-4,85.00$ & 42.35 & 4.5 & 0.1 & 36 \\
$6-5,26.00$ & 43.26 & 4.8 & 0.1 & 39 \\
& & & & \\
\hline & & & & \\
5 & & &
\end{tabular}


TABLE 1 - Continued

\begin{tabular}{|c|c|c|c|c|}
\hline $\begin{array}{l}\text { Core, Section } \\
\text { Top of } \\
\text { Interval } \\
\text { (cm) }\end{array}$ & $\begin{array}{c}\text { Depth } \\
\text { in Hole } \\
\text { (m) }\end{array}$ & $\begin{array}{c}\text { Carbon } \\
\text { Total } \\
(\%)\end{array}$ & $\begin{array}{c}\text { Organic } \\
\text { Carbon } \\
(\%)\end{array}$ & $\begin{array}{c}\mathrm{CaCO}_{3} \\
(\%)\end{array}$ \\
\hline $\begin{array}{l}6-6,25.00 \\
6-6,83.00\end{array}$ & $\begin{array}{l}44.75 \\
45.33\end{array}$ & $\begin{array}{l}4.4 \\
6.1\end{array}$ & $\begin{array}{l}0.2 \\
0.2\end{array}$ & $\begin{array}{l}35 \\
49\end{array}$ \\
\hline $\begin{array}{l}7-1,31.00 \\
7-2,5.00 \\
7-4,8.00 \\
7-5,7.00 \\
7-6,116.00\end{array}$ & $\begin{array}{l}46.31 \\
47.55 \\
50.58 \\
52.07 \\
54.66\end{array}$ & $\begin{array}{l}5.6 \\
5.4 \\
5.6 \\
5.0 \\
5.4\end{array}$ & $\begin{array}{l}0.2 \\
0.0 \\
0.2 \\
0.1 \\
0.2\end{array}$ & $\begin{array}{l}45 \\
44 \\
45 \\
40 \\
44\end{array}$ \\
\hline $\begin{array}{l}8-1,53.00 \\
8-1,120.00 \\
8-2,77.00 \\
8-2,97.00 \\
8-3,17.00 \\
8-3,116.00 \\
8-4,28.00 \\
8-5,42.00 \\
8-6,8.00 \\
8-6,147.00\end{array}$ & $\begin{array}{l}56.53 \\
57.20 \\
58.27 \\
58.47 \\
59.17 \\
60.16 \\
60.78 \\
62.42 \\
63.58 \\
64.97\end{array}$ & $\begin{array}{l}5.2 \\
5.2 \\
3.0 \\
5.5 \\
6.2 \\
4.3 \\
4.0 \\
5.9 \\
4.4 \\
4.3\end{array}$ & $\begin{array}{l}0.2 \\
0.1 \\
0.2 \\
0.1 \\
0.1 \\
0.1 \\
0.1 \\
0.1 \\
0.1 \\
0.1\end{array}$ & $\begin{array}{l}42 \\
42 \\
24 \\
45 \\
51 \\
35 \\
33 \\
48 \\
36 \\
34\end{array}$ \\
\hline $\begin{array}{l}9-1,44.00 \\
9-2,9.00 \\
9-2,109.00 \\
9-3,80.00 \\
9-4,15.00 \\
9-5,20.00 \\
9-5,72.00 \\
9-5,116.00 \\
9-6,4.00 \\
9-6,25.00 \\
9-6,34.00 \\
9-6,59.00 \\
9-6,137.00\end{array}$ & $\begin{array}{l}65.44 \\
66.59 \\
67.59 \\
68.80 \\
69.65 \\
71.20 \\
71.72 \\
72.16 \\
72.54 \\
72.75 \\
72.84 \\
73.09 \\
73.87\end{array}$ & $\begin{array}{l}2.8 \\
4.6 \\
4.6 \\
4.4 \\
4.9 \\
5.9 \\
4.8 \\
1.7 \\
3.4 \\
0.5 \\
4.5 \\
0.3 \\
0.4\end{array}$ & $\begin{array}{l}0.3 \\
0.2 \\
0.2 \\
0.2 \\
0.3 \\
0.2 \\
0.1 \\
0.2 \\
0.2 \\
0.2 \\
0.2 \\
0.2 \\
0.2\end{array}$ & $\begin{array}{r}21 \\
23 \\
36 \\
35 \\
38 \\
48 \\
39 \\
12 \\
26 \\
2 \\
37 \\
37 \\
0 \\
1\end{array}$ \\
\hline $\begin{array}{l}10-1,103.00 \\
10-2,19.00 \\
10-3,4.00 \\
10-4,69.00 \\
10-4,128.00 \\
10-5,38.00 \\
10-5,100.00\end{array}$ & $\begin{array}{l}76.03 \\
76.69 \\
78.04 \\
80.19 \\
80.78 \\
81.38 \\
82.00\end{array}$ & $\begin{array}{l}0.2 \\
0.2 \\
0.3 \\
4.3 \\
0.3 \\
0.2 \\
3.3\end{array}$ & $\begin{array}{l}0.2 \\
0.2 \\
0.2 \\
0.2 \\
0.2 \\
0.2 \\
0.2\end{array}$ & $\begin{array}{r}0 \\
0 \\
1 \\
34 \\
1 \\
0 \\
25\end{array}$ \\
\hline $\begin{array}{l}11-1,43.00 \\
11-2,8.00 \\
11-2,100.00 \\
11-3,112.00 \\
11-3,122.00 \\
11-4,7.00 \\
11-4,73.00 \\
11-5,14.00 \\
11-5,83.00 \\
11-6,44.00 \\
11-6,139.00\end{array}$ & $\begin{array}{l}84.43 \\
85.58 \\
86.50 \\
88.12 \\
88.22 \\
88.57 \\
89.23 \\
90.14 \\
90.83 \\
91.94 \\
92.89\end{array}$ & $\begin{array}{l}0.4 \\
0.4 \\
0.5 \\
0.2 \\
0.2 \\
0.0 \\
1.7 \\
1.2 \\
0.1 \\
1.6 \\
0.0\end{array}$ & $\begin{array}{l}0.2 \\
0.2 \\
0.2 \\
0.2 \\
0.2 \\
0.0 \\
0.2 \\
0.2 \\
0.2 \\
0.2 \\
0.2\end{array}$ & $\begin{array}{r}2 \\
1 \\
2 \\
0 \\
0 \\
0 \\
13 \\
8 \\
0 \\
12 \\
0\end{array}$ \\
\hline $\begin{array}{l}12-1,30.00 \\
12-2,76.00 \\
12-2,121.00 \\
12-3,25.00 \\
12-3,89.00 \\
12-4,33.00 \\
12-4,80.00 \\
12-5,3.00 \\
12-6,14.00 \\
12-6,84.00 \\
12-6,128.00\end{array}$ & $\begin{array}{r}93.30 \\
95.26 \\
95.71 \\
96.25 \\
96.89 \\
97.83 \\
98.30 \\
99.03 \\
100.64 \\
101.34 \\
101.78\end{array}$ & $\begin{array}{l}1.3 \\
3.9 \\
2.3 \\
2.6 \\
6.4 \\
2.4 \\
6.7 \\
6.4 \\
4.7 \\
4.5 \\
5.4\end{array}$ & $\begin{array}{l}0.2 \\
0.2 \\
0.2 \\
0.2 \\
0.1 \\
0.2 \\
0.1 \\
0.1 \\
0.1 \\
0.1 \\
0.1\end{array}$ & $\begin{array}{l}10 \\
30 \\
18 \\
20 \\
52 \\
19 \\
55 \\
52 \\
38 \\
37 \\
44\end{array}$ \\
\hline $\begin{array}{l}13-1,30.00 \\
13-1,74.00 \\
13-1,122.00 \\
13-2,5.00\end{array}$ & $\begin{array}{l}102.30 \\
102.74 \\
103.22 \\
103.55\end{array}$ & $\begin{array}{l}0.1 \\
0.3 \\
0.2 \\
0.5\end{array}$ & $\begin{array}{l}0.1 \\
0.1 \\
0.1 \\
0.1\end{array}$ & $\begin{array}{l}0 \\
1 \\
0 \\
3\end{array}$ \\
\hline
\end{tabular}

TABLE 1 - Continued

\begin{tabular}{|c|c|c|c|c|}
\hline $\begin{array}{l}\text { Core, Section } \\
\text { Top of } \\
\text { Interval } \\
\text { (cm) }\end{array}$ & $\begin{array}{l}\text { Depth } \\
\text { in Hole } \\
(\mathrm{m})\end{array}$ & $\begin{array}{c}\text { Carbon } \\
\text { Total } \\
(\%)\end{array}$ & $\begin{array}{c}\text { Organic } \\
\text { Carbon } \\
(\%)\end{array}$ & $\begin{array}{c}\mathrm{CaCO}_{3} \\
(\%)\end{array}$ \\
\hline $\begin{array}{l}13-2,56.00 \\
13-2,89.00 \\
13-2,129.00 \\
13-3,4.00 \\
13-3,62.00 \\
13-3,137.00 \\
13-4,139.00 \\
13-5,135.00 \\
13-6,52.00 \\
13-6,55.00\end{array}$ & $\begin{array}{l}104.06 \\
104.39 \\
104.79 \\
105.04 \\
105.62 \\
106.37 \\
107.89 \\
109.35 \\
110.02 \\
110.05\end{array}$ & $\begin{array}{l}6.7 \\
1.2 \\
3.0 \\
3.6 \\
4.5 \\
5.6 \\
4.1 \\
6.8 \\
5.3 \\
0.4\end{array}$ & $\begin{array}{l}0.1 \\
0.1 \\
0.1 \\
0.1 \\
0.1 \\
0.1 \\
0.1 \\
0.1 \\
0.1 \\
0.0\end{array}$ & $\begin{array}{r}55 \\
9 \\
24 \\
29 \\
37 \\
46 \\
33 \\
56 \\
44 \\
3\end{array}$ \\
\hline $\begin{array}{l}14-2,131.00 \\
14-3,90.00 \\
14-4,6.00 \\
14-4,91.00 \\
14-4,120.00 \\
14-4,142.00\end{array}$ & $\begin{array}{l}114.81 \\
115.90 \\
116.56 \\
117.41 \\
117.70 \\
117.92\end{array}$ & $\begin{array}{l}0.4 \\
4.5 \\
0.0 \\
0.0 \\
0.1 \\
0.1\end{array}$ & $\begin{array}{l}0.1 \\
0.0 \\
0.1 \\
0.1 \\
0.0 \\
0.1\end{array}$ & $\begin{array}{r}3 \\
37 \\
0 \\
0 \\
0 \\
0\end{array}$ \\
\hline $\begin{array}{l}15-1,39.00 \\
15-1,112.00 \\
15-2,22.00 \\
15-2,111.00 \\
15-2,123.00 \\
15-3,22.00 \\
15-3,37.00 \\
15-4,139.00 \\
15-4,146.00 \\
15-5,26.00 \\
15-5,101.00\end{array}$ & $\begin{array}{l}121.39 \\
122.12 \\
122.72 \\
123.61 \\
123.73 \\
124.22 \\
124.37 \\
126.89 \\
126.96 \\
127.26 \\
128.01\end{array}$ & $\begin{array}{l}0.1 \\
0.0 \\
0.0 \\
0.2 \\
3.9 \\
6.8 \\
1.4 \\
2.6 \\
5.7 \\
0.6 \\
1.8\end{array}$ & $\begin{array}{l}0.1 \\
0.0 \\
0.1 \\
0.0 \\
0.0 \\
0.0 \\
0.1 \\
0.1 \\
0.1 \\
0.1 \\
0.1\end{array}$ & $\begin{array}{r}0 \\
0 \\
0 \\
1 \\
32 \\
56 \\
11 \\
21 \\
47 \\
4 \\
14\end{array}$ \\
\hline $\begin{array}{l}16-1,55.00 \\
16-1,79.00 \\
16-1,100.00 \\
16-1,130.00 \\
16-2,14.00 \\
16-2,38.00 \\
16-3,29.00 \\
16-3,86.00 \\
16-4,116.00 \\
16-4,134.00 \\
16-5,23.00 \\
16-5,33.00 \\
16-5,46.00 \\
16-5,62.00\end{array}$ & $\begin{array}{l}130.55 \\
130.79 \\
131.00 \\
131.30 \\
131.64 \\
150.88 \\
133.29 \\
133.86 \\
135.66 \\
135.84 \\
136.23 \\
136.33 \\
136.46 \\
136.62\end{array}$ & $\begin{array}{l}2.1 \\
0.2 \\
5.2 \\
3.7 \\
0.0 \\
8.9^{*} \\
4.6 \\
0.4 \\
7.9 \\
4.4 \\
1.5 \\
5.0 \\
7.1 \\
3.3\end{array}$ & $\begin{array}{l}0.1 \\
0.1 \\
0.1 \\
0.1 \\
0.1 \\
0.2^{*} \\
0.0 \\
0.1 \\
0.0 \\
0.0 \\
0.1 \\
0.0 \\
0.0 \\
0.0\end{array}$ & $\begin{array}{r}17 \\
1 \\
43 \\
30 \\
0 \\
31 \\
38 \\
3 \\
65 \\
36 \\
12 \\
41 \\
59 \\
28\end{array}$ \\
\hline $\begin{array}{l}17-3,63.00 \\
17-4,13.00 \\
17-4,49.00 \\
17-5,31.00 \\
17-5,67.00 \\
17-5,90.00\end{array}$ & $\begin{array}{l}142.63 \\
143.63 \\
143.99 \\
145.31 \\
145.67 \\
145.90\end{array}$ & $\begin{array}{l}6.5 \\
7.7 \\
5.3 \\
7.0 \\
5.8 \\
8.8\end{array}$ & $\begin{array}{l}0.0 \\
0.1 \\
0.0 \\
0.0 \\
0.0 \\
0.1\end{array}$ & $\begin{array}{l}54 \\
63 \\
44 \\
58 \\
48 \\
72\end{array}$ \\
\hline $\begin{array}{l}18-1,57.00 \\
18-2,15.00 \\
18-2,32.00 \\
18-3,10.00 \\
18-3,56.00 \\
18-4,15.00 \\
18-4,144.00 \\
18-5,35.00 \\
18-5,71.00\end{array}$ & $\begin{array}{l}149.57 \\
150.65 \\
150.82 \\
152.10 \\
152.56 \\
153.65 \\
154.94 \\
155.35 \\
155.71\end{array}$ & $\begin{array}{l}8.3 \\
8.9 \\
5.8 \\
9.6^{*} \\
7.8^{*} \\
7.6^{*} \\
5.6^{*} \\
8.7^{*} \\
6.8^{*}\end{array}$ & $\begin{array}{l}0.0 \\
0.0 \\
0.0 \\
0.1^{*} \\
0.1^{*} \\
0.1^{*} \\
0.1^{*} \\
0.1^{*} \\
0.1^{*}\end{array}$ & $\begin{array}{l}69 \\
74 \\
48 \\
79 \\
64 \\
62 \\
45 \\
72 \\
55\end{array}$ \\
\hline $\begin{array}{l}19-1,138.00 \\
19-1,144.00 \\
19-2,48.00 \\
19-2,86.00 \\
19-2,107.00 \\
19-3,38.00 \\
19-3,79.00 \\
19-3,120.00\end{array}$ & $\begin{array}{l}159.38 \\
159.44 \\
159.98 \\
160.36 \\
160.57 \\
161.38 \\
161.79 \\
162.20\end{array}$ & $\begin{array}{l}8.7^{*} \\
4.9^{*} \\
4.3^{*} \\
8.8^{*} \\
7.7^{*} \\
7.5^{*} \\
3.2^{*} \\
4.0^{*}\end{array}$ & $\begin{array}{l}0.1^{*} \\
0.2^{*} \\
0.2^{*} \\
0.1^{*} \\
0.1^{*} \\
0.1^{*} \\
0.2^{*} \\
0.2^{*}\end{array}$ & $\begin{array}{l}71 \\
39 \\
34 \\
72 \\
63 \\
62 \\
25 \\
32\end{array}$ \\
\hline
\end{tabular}


TABLE 1 - Continued

\begin{tabular}{|c|c|c|c|c|}
\hline $\begin{array}{l}\text { Core, Section } \\
\text { Top of } \\
\text { Interval } \\
\text { (cm) }\end{array}$ & $\begin{array}{l}\text { Depth } \\
\text { in Hole } \\
(\mathrm{m})\end{array}$ & $\begin{array}{c}\text { Carbon } \\
\text { Total } \\
(\%)\end{array}$ & $\begin{array}{c}\text { Organic } \\
\text { Carbon } \\
(\%)\end{array}$ & $\begin{array}{c}\mathrm{CaCO}_{3} \\
(\%)\end{array}$ \\
\hline $\begin{array}{l}20-1,132.00 \\
20-2,24.00 \\
20-2,85.00 \\
20-2,118.00 \\
20-3,21.00 \\
20-3,138.00 \\
20-4,12.00 \\
20-4,76.00 \\
20-5,36.00 \\
20-5,124.00\end{array}$ & $\begin{array}{l}168.32 \\
168.74 \\
169.35 \\
169.68 \\
170.21 \\
171.38 \\
171.62 \\
172.26 \\
173.36 \\
174.24\end{array}$ & $\begin{array}{l}5.6^{*} \\
6.4^{*} \\
9.0^{*} \\
7.8^{*} \\
8.6^{*} \\
5.6^{*} \\
3.3^{*} \\
8.9^{*} \\
6.6^{*} \\
8.2^{*}\end{array}$ & $\begin{array}{l}0.2^{*} \\
0.1^{*} \\
0.2^{*} \\
0.1^{*} \\
0.1^{*} \\
0.1^{*} \\
0.2^{*} \\
0.0^{*} \\
0.1^{*} \\
0.1^{*}\end{array}$ & $\begin{array}{l}45 \\
52 \\
74 \\
64 \\
71 \\
46 \\
25 \\
74 \\
54 \\
68\end{array}$ \\
\hline $\begin{array}{l}21-1,96.00 \\
21-4,82.00 \\
21-5,6.00 \\
21-5,78.00\end{array}$ & $\begin{array}{l}176.96 \\
181.32 \\
182.06 \\
182.78\end{array}$ & $\begin{array}{l}7.7^{*} \\
4.9^{*} \\
7.0^{*} \\
4.1^{*}\end{array}$ & $\begin{array}{l}0.1^{*} \\
0.1^{*} \\
0.1^{*} \\
0.1^{*}\end{array}$ & $\begin{array}{l}63 \\
40 \\
57 \\
33\end{array}$ \\
\hline $22-6,120.00$ & 193.70 & $6.7^{*}$ & $0.1^{*}$ & 55 \\
\hline $\begin{array}{l}23-2,145.00 \\
23-3,12.00 \\
23-3,57.00 \\
23-4,48.00 \\
23-4,135.00 \\
23-5,75.00 \\
23-5,135.00\end{array}$ & $\begin{array}{l}197.95 \\
198.12 \\
198.57 \\
199.98 \\
200.85 \\
201.75 \\
202.35\end{array}$ & $\begin{array}{l}8.7^{*} \\
9.5^{*} \\
9.4^{*} \\
7.8^{*} \\
9.2^{*} \\
9.5^{*} \\
6.7^{*}\end{array}$ & $\begin{array}{l}0.1^{*} \\
0.1^{*} \\
0.2^{*} \\
0.1^{*} \\
0.1^{*} \\
0.1^{*} \\
0.2^{*}\end{array}$ & $\begin{array}{l}72 \\
78 \\
77 \\
64 \\
76 \\
79 \\
54\end{array}$ \\
\hline $\begin{array}{l}24-1,101.00 \\
25-1,77.00 \\
25-2,106.00 \\
25-3,14.00 \\
25-3,135.00\end{array}$ & $\begin{array}{l}205.01 \\
213.77 \\
215.56 \\
216.14 \\
217.35\end{array}$ & $\begin{array}{l}5.7^{*} \\
7.7^{*} \\
7.4^{*} \\
8.4^{*} \\
7.6^{*}\end{array}$ & $\begin{array}{l}0.2^{*} \\
0.1^{*} \\
0.2^{*} \\
0.2^{*} \\
0.1^{*}\end{array}$ & $\begin{array}{l}46 \\
63 \\
60 \\
69 \\
63\end{array}$ \\
\hline $\begin{array}{l}26-1,128.00 \\
26-1,132.00 \\
26-2,66.00 \\
26-3,15.00\end{array}$ & $\begin{array}{l}224.28 \\
224.32 \\
225.16 \\
226.15\end{array}$ & $\begin{array}{l}7.3^{*} \\
7.7^{*} \\
6.5^{*} \\
7.4^{*}\end{array}$ & $\begin{array}{l}0.1^{*} \\
0.1^{*} \\
0.1^{*} \\
0.1^{*}\end{array}$ & $\begin{array}{l}60 \\
63 \\
54 \\
61\end{array}$ \\
\hline $\begin{array}{l}27-1,119.00 \\
27-2,75.00 \\
27-3,16.00 \\
27-3,47.00\end{array}$ & $\begin{array}{l}233.19 \\
234.25 \\
235.16 \\
235.47\end{array}$ & $\begin{array}{l}6.6^{*} \\
4.9^{*} \\
3.7^{*} \\
4.6^{*}\end{array}$ & $\begin{array}{l}0.1^{*} \\
0.1^{*} \\
0.1^{*} \\
0.1^{*}\end{array}$ & $\begin{array}{l}55 \\
40 \\
30 \\
37\end{array}$ \\
\hline $\begin{array}{l}28-1,103.00 \\
28-2,73.00 \\
28-2,135.00 \\
28-3,76.00 \\
28-4,14.00 \\
28-4,144.00\end{array}$ & $\begin{array}{l}242.03 \\
243.23 \\
243.85 \\
244.76 \\
245.64 \\
246.94\end{array}$ & $\begin{array}{l}6.0^{*} \\
6.2^{*} \\
3.3^{*} \\
3.7^{*} \\
4.9^{*} \\
6.5^{*}\end{array}$ & $\begin{array}{l}0.1^{*} \\
0.1^{*} \\
0.1^{*} \\
0.1^{*} \\
0.1^{*} \\
0.1^{*}\end{array}$ & $\begin{array}{l}50 \\
51 \\
27 \\
30 \\
40 \\
53\end{array}$ \\
\hline $\begin{array}{l}29-1,127.00 \\
29-2,75.00 \\
29-3,106.00\end{array}$ & $\begin{array}{l}252.27 \\
253.25 \\
255.06\end{array}$ & $\begin{array}{l}7.9^{*} \\
8.7^{*} \\
7.1^{*}\end{array}$ & $\begin{array}{l}0.1^{*} \\
0.1^{*} \\
0.1^{*}\end{array}$ & $\begin{array}{l}65 \\
72 \\
58\end{array}$ \\
\hline $30-2,4.00$ & 261.54 & $8.3^{*}$ & $0.2 *$ & 68 \\
\hline $\begin{array}{l}31-1,75.00 \\
31-2,75.00\end{array}$ & $\begin{array}{l}270.75 \\
272.25\end{array}$ & $\begin{array}{l}1.9^{*} \\
0.6^{*}\end{array}$ & $\begin{array}{l}0.1^{*} \\
0.1^{*}\end{array}$ & $\begin{array}{r}15 \\
4\end{array}$ \\
\hline $\begin{array}{l}32-2,19.00 \\
32-3,32.00 \\
32-4,58.00\end{array}$ & $\begin{array}{l}280.69 \\
282.32 \\
284.08\end{array}$ & $\begin{array}{l}1.4^{*} \\
1.9^{*} \\
4.3^{*}\end{array}$ & $\begin{array}{l}0.1^{*} \\
0.1^{*} \\
0.1^{*}\end{array}$ & $\begin{array}{l}11 \\
16 \\
36\end{array}$ \\
\hline $\begin{array}{l}33-1,92.00 \\
33-2,133.00\end{array}$ & $\begin{array}{l}288.92 \\
290.83\end{array}$ & $\begin{array}{l}4.1^{*} \\
5.3^{*}\end{array}$ & $\begin{array}{l}0.1^{*} \\
0.1^{*}\end{array}$ & $\begin{array}{l}33 \\
43\end{array}$ \\
\hline $\begin{array}{l}34-2,40.00 \\
34-3,55.0\end{array}$ & $\begin{array}{l}299.90 \\
301.55\end{array}$ & $\begin{array}{l}7.1^{*} \\
7.2^{*}\end{array}$ & $\begin{array}{l}0.1^{*} \\
0.1^{*}\end{array}$ & $\begin{array}{l}58 \\
59\end{array}$ \\
\hline $\begin{array}{l}35-1,16.00 \\
35-1,128.00 \\
35-2,33.00 \\
35-2,120.00 \\
35-3,50.00\end{array}$ & $\begin{array}{l}307.16 \\
308.28 \\
308.83 \\
309.70 \\
310.50\end{array}$ & $\begin{array}{l}4.8^{*} \\
1.3^{*} \\
1.7^{*} \\
1.6^{*} \\
3.9^{*}\end{array}$ & $\begin{array}{l}0.1^{*} \\
0.2^{*} \\
0.1^{*} \\
0.1^{*} \\
0.1^{*}\end{array}$ & $\begin{array}{l}39 \\
10 \\
13 \\
12 \\
32\end{array}$ \\
\hline
\end{tabular}

TABLE 1 - Continued

\begin{tabular}{|c|c|c|c|c|}
\hline $\begin{array}{l}\text { Core, Section } \\
\text { Top of } \\
\text { Interval } \\
\text { (cm) }\end{array}$ & $\begin{array}{l}\text { Depth } \\
\text { in Hole } \\
\text { (m) }\end{array}$ & $\begin{array}{c}\text { Carbon } \\
\text { Total } \\
(\%)\end{array}$ & $\begin{array}{c}\text { Organic } \\
\text { Carbon } \\
(\%)\end{array}$ & $\begin{array}{c}\mathrm{CaCO}_{3} \\
(\%)\end{array}$ \\
\hline $\begin{array}{l}35-4,37.00 \\
35-5,32.00 \\
35-5,99.00 \\
35-6,63.00 \\
35-6,138.00\end{array}$ & $\begin{array}{l}311.87 \\
313.32 \\
313.99 \\
315.13 \\
315.88\end{array}$ & $\begin{array}{l}5.2^{*} \\
2.4^{*} \\
4.7^{*} \\
1.6^{*} \\
5.6^{*}\end{array}$ & $\begin{array}{l}0.2^{*} \\
0.1^{*} \\
0.1^{*} \\
0.1^{*} \\
0.1^{*}\end{array}$ & $\begin{array}{l}42 \\
19 \\
38 \\
13 \\
46\end{array}$ \\
\hline $36-1,103.00$ & 317.03 & $4.5^{*}$ & $0.1^{*}$ & 37 \\
\hline $39-1 ; 130: 00$ & $345: 30$ & $0: 1^{*}$ & $0: 1^{*}$ & 0 \\
\hline $\begin{array}{l}37-1,95.00 \\
37-2,41.00 \\
37-3,27.00 \\
37-4,25.00 \\
37-4,109.00\end{array}$ & $\begin{array}{l}325.95 \\
326.91 \\
328.27 \\
329.75 \\
330.59\end{array}$ & $\begin{array}{l}7.3^{*} \\
6.5^{*} \\
5.3^{*} \\
4.6^{*} \\
3.1^{*}\end{array}$ & $\begin{array}{l}0.1^{*} \\
0.1^{*} \\
0.1^{*} \\
0.1^{*} \\
0.1^{*}\end{array}$ & $\begin{array}{l}60 \\
54 \\
43 \\
38 \\
25\end{array}$ \\
\hline $\begin{array}{l}38-1,139.00 \\
38-2,53.00 \\
38-2,81.00 \\
38-3,35.00 \\
38-3,119.00\end{array}$ & $\begin{array}{l}335.39 \\
336.03 \\
336.31 \\
337.35 \\
338.19\end{array}$ & $\begin{array}{l}2.4^{*} \\
4.1^{*} \\
0.7^{*} \\
4.9^{*} \\
0.2^{*}\end{array}$ & $\begin{array}{l}0.1^{*} \\
0.1^{*} \\
0.1^{*} \\
0.1^{*} \\
0.0^{*}\end{array}$ & $\begin{array}{r}19 \\
34 \\
5 \\
40 \\
2\end{array}$ \\
\hline $39-1,107.00$ & 345.07 & $5.5^{*}$ & $0.1^{*}$ & 45 \\
\hline $\begin{array}{l}40-1,35.00 \\
40-2,27.00\end{array}$ & $\begin{array}{l}353.35 \\
354.77\end{array}$ & $\begin{array}{l}4.9^{*} \\
4.9^{*}\end{array}$ & $\begin{array}{l}0.1^{*} \\
0.1^{*}\end{array}$ & $\begin{array}{l}40 \\
40\end{array}$ \\
\hline $\begin{array}{l}41-1,75.00 \\
41-2,18.00 \\
41-2,86.00 \\
41-3,16.00 \\
41-4,38.00 \\
41-4,125.00 \\
41-5,33.00 \\
41-6,14.00\end{array}$ & $\begin{array}{l}362.75 \\
363.68 \\
364.36 \\
365.16 \\
366.88 \\
367.75 \\
368.33 \\
369.64\end{array}$ & $\begin{array}{l}4.6^{*} \\
3.6^{*} \\
5.8^{*} \\
4.4^{*} \\
3.8^{*} \\
3.4^{*} \\
3.6^{*} \\
6.4^{*}\end{array}$ & $\begin{array}{l}0.1^{*} \\
0.1^{*} \\
0.1^{*} \\
0.1^{*} \\
0.0^{\circ} \\
0.1^{*} \\
0.1^{*} \\
0.1^{*}\end{array}$ & $\begin{array}{l}38 \\
29 \\
48 \\
36 \\
31 \\
28 \\
29 \\
52\end{array}$ \\
\hline $\begin{array}{l}42-1,141.00 \\
42-2,71.00 \\
42-3,15.00 \\
42-3,147.00 \\
42-4,87.00 \\
42-4,125.00\end{array}$ & $\begin{array}{l}372.41 \\
373.21 \\
374.15 \\
375.47 \\
376.37 \\
376.75\end{array}$ & $\begin{array}{l}5.5^{*} \\
5.0^{*} \\
5.9^{*} \\
3.5^{*} \\
7.6^{*} \\
5.1^{*}\end{array}$ & $\begin{array}{l}0.1^{*} \\
0.1^{*} \\
0.1^{*} \\
0.1^{*} \\
0.1^{*} \\
0.1^{*}\end{array}$ & $\begin{array}{l}45 \\
41 \\
48 \\
28 \\
62 \\
42\end{array}$ \\
\hline $43-1,50.00$ & 381.50 & 3.4 & $0.1^{*}$ & 28 \\
\hline
\end{tabular}

Site 150

$\begin{array}{lrccr}1-1,55.00 & 49.55 & 2.8^{*} & 0.4^{*} & 20 \\ 1-1,84.00 & 49.84 & 4.8^{*} & 0.3^{*} & 38 \\ 1-2,135.00 & 51.85 & 0.5 & 0.4^{*} & 1 \\ 1-3,87.00 & 52.87 & 1.6^{*} & 0.3^{*} & 10 \\ 1-4,14.00 & 53.64 & 1.5^{*} & 0.4^{*} & 9 \\ 2-1,99.00 & 77.99 & 0.1 & 0.3^{*} & 0 \\ 2-2,121.00 & 79.71 & 0.1 & 0.3^{*} & 0 \\ 2-3,75.00 & 80.75 & 0.1 & 0.2^{*} & 0 \\ 3-1,146.00 & 87.46 & 0.3^{*} & 0.0 & 2 \\ 3-2,32.00 & 87.82 & 0.1 & 0.2^{*} & 0 \\ 3-3,26.00 & 89.26 & 0.1 & 0.2^{*} & 0 \\ 3-5,83.00 & 92.83 & 0.5^{*} & 0.1^{*} & 3 \\ 4-1,95.00 & 95.95 & 2.5 & 0.2^{*} & 19 \\ 4-1,102.00 & 96.02 & 5.9^{*} & 0.1^{*} & 48 \\ 4-2,111.00 & 97.61 & 7.3 & 0.1^{*} & 60 \\ 4-3,3.00 & 98.03 & 5.0 & 0.1^{*} & 40 \\ 4-3,50.00 & 98.50 & 0.0 & 0.2^{*} & 0 \\ 5-3,130.00 & 109.30 & 0.0 & 0.2^{*} & 0 \\ 9-1,48.00 & 150.48 & 2.7^{*} & 0.1^{*} & 22 \\ 9-1,61.00 & 150.61 & 10.1^{*} & 3.1^{*} & 59 \\ 9-1,116.00 & 151.16 & 0.2^{*} & 0.1^{*} & 1\end{array}$


TABLE 1 - Continued

\begin{tabular}{ccccc}
\hline $\begin{array}{c}\text { Core, Section } \\
\text { Top of } \\
\text { Interval } \\
\text { (cm) }\end{array}$ & $\begin{array}{c}\text { Depth } \\
\text { in Hole } \\
(\mathrm{m})\end{array}$ & $\begin{array}{c}\text { Carbon } \\
\text { Total } \\
(\%)\end{array}$ & $\begin{array}{c}\text { Organic } \\
\text { Carbon } \\
(\%)\end{array}$ & $\begin{array}{c}\mathrm{CaCO}_{3} \\
(\%)\end{array}$ \\
\hline $10-1,25.00$ & 159.25 & $7.8^{*}$ & 0.1 & 64 \\
$10-1,33$ & 159.33 & 9.5 & 0.1 & 79 \\
$10-2,26.00$ & 160.76 & $9.6^{*}$ & $0.1^{*}$ & 79 \\
$10-2,54.00$ & 161.04 & $9.7^{*}$ & $0.1^{*}$ & 81
\end{tabular}

Site 151

$\begin{array}{lrrrc}1-1,74.00 & 61.74 & 8.5^{*} & 0.1^{*} & 70 \\ 1-2,50.00 & 63.00 & 7.8^{*} & 0.1^{*} & 64 \\ 1-3,80.00 & 64.80 & 7.4^{*} & 0.1^{*} & 60 \\ 1-4,48.00 & 65.98 & 6.4^{*} & 0.2^{*} & 52 \\ 1-5,24.00 & 67.24 & 6.5^{*} & 0.1^{*} & 53 \\ 1-6,95.00 & 69.45 & 7.8^{*} & 0.2^{*} & 64 \\ 2-1,99.00 & 117.99 & 6.5^{*} & 0.2^{*} & 53 \\ 2-1,120.00 & 118.20 & 6.5^{*} & 0.1^{*} & 53 \\ 2-2,59.00 & 119.09 & 6.2^{*} & 0.2^{*} & 51 \\ 2-3,59.00 & 120.59 & 7.0^{*} & 0.2^{*} & 57 \\ 3-1,22.00 & 181.22 & 3.0^{*} & 0.3^{*} & 23 \\ 3-1,51.00 & 181.51 & 8.4^{*} & 0.1^{*} & 69 \\ 3-2,41.00 & 182.91 & 8.4^{*} & 0.1^{*} & 69 \\ 3-2,54.00 & 183.04 & 5.2^{*} & 0.2^{*} & 42 \\ 3-3,123.00 & 185.23 & 9.4^{*} & 0.1^{*} & 77 \\ 3-4,13.00 & 185.63 & 6.7^{*} & 0.2^{*} & 54 \\ 3-4,91.00 & 186.41 & 8.4^{*} & 0.0^{*} & 70 \\ 3-5,140.00 & 188.40 & 9.5^{*} & 0.1^{*} & 78 \\ 3-6,35.00 & 188.85 & 9.2^{*} & 0.3^{*} & 75 \\ 4-1,56.00 & 237.56 & 10.5^{*} & 0.0^{*} & 87 \\ 4-2,61.00 & 239.11 & 10.2^{*} & 0.1^{*} & 85 \\ 5-1,90.00 & 302.90 & 10.5^{*} & 0.1^{*} & 87 \\ 5-2,142.00 & 304.92 & 10.6^{*} & 0.0^{*} & 88 \\ 6-1,132.00 & 312.32 & 10.6^{*} & 0.0 & 88 \\ 6-2,86.00 & 313.36 & 10.7^{*} & 0.1 & 88 \\ 6-3,24.00 & 314.24 & 10.5^{*} & 0.1 & 87 \\ 7-1,135.00 & 321.35 & 10.6^{*} & 0.1 & 87 \\ 7-2,113.00 & 322.63 & 10.8^{*} & 0.0 & 89 \\ 8-1,135.00 & 330.35 & 11.0^{*} & 0.0 & 91 \\ 9-1,111.00 & 340.11 & 11.3^{*} & 0.0 & 93 \\ 9-2,132.00 & 341.82 & 10.4^{*} & 0.0 & 87 \\ 10-1,88.00 & 348.88 & 10.9^{*} & 0.0 & 91 \\ 10-2,24.00 & 349.74 & 10.9^{*} & 0.0 & 90 \\ 12-1,26.00 & 367.26 & 12.3^{*} & 4.2 & 67 \\ 12-6,72.00 & 375.22 & 10.7^{*} & 2.7 & 67\end{array}$

Site $\mathbf{1 5 2}$

$\begin{array}{lrrrr}1-1,148.00 & 154.48 & 9.3^{*} & 0.1 & 77 \\ 1-2,129.00 & 155.79 & 9.3^{*} & 0.1 & 77 \\ 2-1,141.00 & 163.41 & 2.1 & 0.0 & 17 \\ 2-2,94.00 & 164.44 & 8.3 & 0.0 & 69 \\ 2-3,82.00 & 165.82 & 10.3 & 0.0 & 86 \\ 2-4,19.00 & 166.69 & 9.8 & 0.0 & 81 \\ 2-4,74.00 & 167.24 & 9.6 & 0.0 & 80 \\ 2-5,69.00 & 168.69 & 10.0 & 0.0 & 83 \\ 3-2,101.00 & 174.51 & 9.9 & 0.0 & 83 \\ 3-2,132.00 & 174.82 & 10.2 & 0.0 & 85 \\ 3-3,116.00 & 176.16 & 10.3 & 0.0 & 85 \\ 3-3,129.00 & 176.29 & 10.3 & 0.0 & 85 \\ 3-4,80.00 & 177.30 & 9.0 & 0.0 & 75 \\ 3-5,46.00 & 178.46 & 9.3 & 0.0 & 77 \\ 3-5,92.00 & 178.92 & 7.9 & 0.0 & .65\end{array}$

TABLE 1 - Continued

\begin{tabular}{|c|c|c|c|c|}
\hline $\begin{array}{l}\text { Core, Section } \\
\text { Top of } \\
\text { Interval } \\
\text { (cm) }\end{array}$ & $\begin{array}{l}\text { Depth } \\
\text { in Hole } \\
(\mathrm{m})\end{array}$ & $\begin{array}{c}\text { Carbon } \\
\text { Total } \\
(\%)\end{array}$ & $\begin{array}{c}\text { Organic } \\
\text { Carbon } \\
(\%)\end{array}$ & $\begin{array}{c}\mathrm{CaCO}_{3} \\
(\%)\end{array}$ \\
\hline $\begin{array}{l}4-2,86.00 \\
4-3,96.00\end{array}$ & $\begin{array}{l}184.36 \\
185.96\end{array}$ & $\begin{array}{r}10.2 \\
8.4\end{array}$ & $\begin{array}{l}0.0 \\
0.0\end{array}$ & $\begin{array}{l}85 \\
69\end{array}$ \\
\hline $\begin{array}{l}6-1,63.00 \\
6-2,28.00 \\
6-5,103.00\end{array}$ & $\begin{array}{l}201.63 \\
202.78 \\
208.03\end{array}$ & $\begin{array}{l}8.1 \\
7.6 \\
7.8\end{array}$ & $\begin{array}{l}0.1 \\
0.1 \\
0.1\end{array}$ & $\begin{array}{l}67 \\
63 \\
64\end{array}$ \\
\hline $\begin{array}{l}7-2,10.00 \\
7-3,66.00 \\
7-4,48.00 \\
7-4,78.00 \\
7-4,115.00\end{array}$ & $\begin{array}{l}212.60 \\
214.66 \\
215.98 \\
216.28 \\
216.65\end{array}$ & $\begin{array}{r}11.2 \\
7.8 \\
6.5 \\
8.3 \\
8.7\end{array}$ & $\begin{array}{l}0.0 \\
0.1 \\
0.1 \\
0.1 \\
0.0\end{array}$ & $\begin{array}{l}93 \\
64 \\
53 \\
69 \\
72\end{array}$ \\
\hline $\begin{array}{l}8-1,19.00 \\
8-1,57.00\end{array}$ & $\begin{array}{l}220.19 \\
220.57\end{array}$ & $\begin{array}{l}3.2 \\
8.8\end{array}$ & $\begin{array}{l}0.0 \\
0.0\end{array}$ & $\begin{array}{l}27 \\
74\end{array}$ \\
\hline $9-1,93.00$ & 229.93 & 7.9 & 0.0 & 66 \\
\hline $14-1,107.00$ & 277.07 & 10.4 & 0.0 & 86 \\
\hline $15-2,4.00$ & 287.54 & 10.0 & 0.0 & 83 \\
\hline $\begin{array}{l}16-1,50.00 \\
16-3,141.00 \\
16-7,0.00\end{array}$ & $\begin{array}{l}342.50 \\
346.41 \\
351.00\end{array}$ & $\begin{array}{r}9.9 \\
10.3 \\
11.1\end{array}$ & $\begin{array}{l}0.1 \\
0.0 \\
0.0\end{array}$ & $\begin{array}{l}82 \\
86 \\
92\end{array}$ \\
\hline $\begin{array}{l}17-1,60.00 \\
17-2,7.00\end{array}$ & $\begin{array}{l}398.60 \\
399.57\end{array}$ & $\begin{array}{l}11.0 \\
10.9\end{array}$ & $\begin{array}{l}0.0 \\
0.0\end{array}$ & $\begin{array}{l}92 \\
90\end{array}$ \\
\hline $\begin{array}{l}18-1,72.00 \\
18-2,63.00\end{array}$ & $\begin{array}{l}407.72 \\
409.13\end{array}$ & $\begin{array}{l}11.1 \\
11.0\end{array}$ & $\begin{array}{l}0.0 \\
0.0\end{array}$ & $\begin{array}{l}92 \\
91\end{array}$ \\
\hline $19-1,103.00$ & 417.03 & 10.9 & 0.0 & 90 \\
\hline $21-1,84.00$ & 453.84 & 11.1 & 0.0 & 92 \\
\hline $\begin{array}{l}22-1,0.00 \\
22-2,97.00 \\
22-3,43.00\end{array}$ & $\begin{array}{l}462.00 \\
464.47 \\
465.43\end{array}$ & $\begin{array}{l}9.4 \\
6.6 \\
7.8\end{array}$ & $\begin{array}{l}0.0 \\
0.0 \\
0.2\end{array}$ & $\begin{array}{l}78 \\
55 \\
64\end{array}$ \\
\hline $\begin{array}{l}23-1,37.00 \\
23-7,0.00\end{array}$ & $\begin{array}{l}471.37 \\
480.00\end{array}$ & $\begin{array}{r}8.0 \\
10.7\end{array}$ & $\begin{array}{l}0.0 \\
0.0\end{array}$ & $\begin{array}{l}67 \\
88\end{array}$ \\
\hline \multicolumn{5}{|l|}{ Site 153} \\
\hline $\begin{array}{l}1-1,110.00 \\
1-2,100.00 \\
1-3,135.00\end{array}$ & $\begin{array}{l}103.10 \\
104.50 \\
106.35\end{array}$ & $\begin{array}{l}2.8 \\
2.5 \\
1.8\end{array}$ & $\begin{array}{l}0.3 \\
0.3 \\
0.4\end{array}$ & $\begin{array}{l}21 \\
18 \\
11\end{array}$ \\
\hline $2-1,90.00$ & 198.90 & 0.6 & 0.4 & 2 \\
\hline $\begin{array}{l}3-1,83.00 \\
3-2,50.00\end{array}$ & $\begin{array}{l}207.83 \\
209.00\end{array}$ & $\begin{array}{l}0.5 \\
0.4\end{array}$ & $\begin{array}{l}0.3 \\
0.2\end{array}$ & $\begin{array}{l}2 \\
2\end{array}$ \\
\hline $\begin{array}{l}4-1,89.00 \\
4-1,108.00 \\
4-2,20.00 \\
4-2,46.00 \\
4-2,116.00 \\
4-3,42.00 \\
4-3,57.00 \\
4-4,48.00 \\
4-5,49.00 \\
4-6,38.00\end{array}$ & $\begin{array}{l}300.89 \\
301.08 \\
301.70 \\
301.96 \\
302.66 \\
303.42 \\
303.57 \\
304.98 \\
306.49 \\
307.88\end{array}$ & $\begin{array}{l}5.9 \\
0.5 \\
0.6 \\
2.6 \\
4.7 \\
5.0 \\
0.4 \\
1.8 \\
2.5 \\
3.1\end{array}$ & $\begin{array}{l}0.1 \\
0.4 \\
0.3 \\
0.2 \\
0.1 \\
0.1 \\
0.3 \\
0.2 \\
0.2 \\
0.1\end{array}$ & $\begin{array}{r}48 \\
1 \\
2 \\
20 \\
38 \\
41 \\
0 \\
14 \\
20 \\
25\end{array}$ \\
\hline $\begin{array}{l}5-1,64.00 \\
5-2,35.00 \\
5-3,29.00 \\
5-4,18.00 \\
5-4,138.00\end{array}$ & $\begin{array}{l}403.64 \\
404.85 \\
406.29 \\
407.68 \\
408.88\end{array}$ & $\begin{array}{l}6.6 \\
7.8 \\
7.7 \\
4.3 \\
9.7\end{array}$ & $\begin{array}{l}0.0 \\
0.0 \\
0.0 \\
0.0 \\
0.0\end{array}$ & $\begin{array}{l}54 \\
65 \\
64 \\
35 \\
81\end{array}$ \\
\hline $\begin{array}{l}6-1,36.00 \\
6-2,131.00 \\
6-2,131.00\end{array}$ & $\begin{array}{l}412.36 \\
414.81 \\
414.81\end{array}$ & $\begin{array}{l}9.9 \\
9.7 \\
9.8\end{array}$ & $\begin{array}{l}0.0 \\
0.0 \\
0.0\end{array}$ & $\begin{array}{l}83 \\
81 \\
82\end{array}$ \\
\hline $\begin{array}{l}7-1,112.00 \\
7-1,112.00\end{array}$ & $\begin{array}{l}500.12 \\
500.12\end{array}$ & $\begin{array}{l}9.9 \\
9.8\end{array}$ & $\begin{array}{l}0.0 \\
0.0\end{array}$ & $\begin{array}{l}82 \\
81\end{array}$ \\
\hline
\end{tabular}


TABLE 1 - Continued

\begin{tabular}{|c|c|c|c|c|}
\hline $\begin{array}{l}\text { Core, Section } \\
\text { Top of } \\
\text { Interval } \\
\text { (cm) }\end{array}$ & $\begin{array}{l}\text { Depth } \\
\text { in Hole } \\
(\mathrm{m})\end{array}$ & $\begin{array}{c}\text { Carbon } \\
\text { Total } \\
(\%)\end{array}$ & $\begin{array}{c}\text { Organic } \\
\text { Carbon } \\
(\%)\end{array}$ & $\begin{array}{c}\mathrm{CaCO}_{3} \\
(\%)\end{array}$ \\
\hline $8-1,82.00$ & 563.82 & 10.3 & 0.0 & 85 \\
\hline $\begin{array}{l}9-1,139.00 \\
9-2,126.50\end{array}$ & $\begin{array}{l}587.39 \\
588.77\end{array}$ & $\begin{array}{l}5.9 \\
2.9\end{array}$ & $\begin{array}{l}0.0 \\
0.0\end{array}$ & $\begin{array}{l}49 \\
24\end{array}$ \\
\hline $\begin{array}{l}10-2,19.00 \\
10-2,103.00\end{array}$ & $\begin{array}{l}592.69 \\
593.53\end{array}$ & $\begin{array}{l}5.7 \\
0.0\end{array}$ & $\begin{array}{l}0.0 \\
0.0\end{array}$ & $\begin{array}{r}47 \\
0\end{array}$ \\
\hline $\begin{array}{l}11-1,68.00 \\
11-2,132.00 \\
22-3,72.50 \\
11-3,120.50\end{array}$ & $\begin{array}{l}600.68 \\
602.82 \\
603.72 \\
604.20\end{array}$ & $\begin{array}{l}5.5 \\
3.2 \\
6.9 \\
5.9\end{array}$ & $\begin{array}{l}0.0 \\
0.0 \\
0.0 \\
0.0\end{array}$ & $\begin{array}{l}46 \\
27 \\
57 \\
49\end{array}$ \\
\hline $\begin{array}{l}12-1,79.00 \\
12-1,146.00 \\
12-2,0.00 \\
12-2,41.00 \\
12-3,130.00\end{array}$ & $\begin{array}{l}609.79 \\
610.46 \\
610.50 \\
610.91 \\
613.30\end{array}$ & $\begin{array}{l}1.7 \\
8.2 \\
7.8 \\
8.4 \\
4.4\end{array}$ & $\begin{array}{l}0.0 \\
0.0 \\
0.0 \\
0.0 \\
0.0\end{array}$ & $\begin{array}{l}14 \\
68 \\
64 \\
70 \\
37\end{array}$ \\
\hline $\begin{array}{l}13-1,126.00 \\
13-2,149.00 \\
13-3,70.00 \\
13-4,13.00 \\
13-4,130.00\end{array}$ & $\begin{array}{l}620.26 \\
621.99 \\
622.70 \\
623.63 \\
624.80\end{array}$ & $\begin{array}{r}7.7 \\
1.1 \\
9.6 \\
10.1 \\
8.4\end{array}$ & $\begin{array}{l}0.0 \\
0.0 \\
0.0 \\
0.0 \\
0.0\end{array}$ & $\begin{array}{r}64 \\
9 \\
79 \\
84 \\
70\end{array}$ \\
\hline $14-1,102.00$ & 657.02 & 10.8 & 0.0 & 90 \\
\hline $\begin{array}{l}15-1,62.00 \\
15-2,73.00 \\
15-2,109.00 \\
15-3,38.00 \\
15-3,105.00 \\
15-4,134.00\end{array}$ & $\begin{array}{l}667.62 \\
669.23 \\
669.59 \\
670.38 \\
671.05 \\
672.84\end{array}$ & $\begin{array}{r}9.4 \\
0.1 \\
10.1 \\
10.4 \\
8.5 \\
8.9\end{array}$ & $\begin{array}{l}0.6 \\
0.0 \\
0.0 \\
0.0 \\
0.0 \\
0.1\end{array}$ & $\begin{array}{r}73 \\
1 \\
84 \\
87 \\
71 \\
74\end{array}$ \\
\hline $\begin{array}{l}16-1,6.00 \\
16-1,19.00 \\
16-1,87.00 \\
16-2,13.00 \\
16-2,22.00 \\
16-2,34.00 \\
16-2,37.00 \\
16-2,102.00\end{array}$ & $\begin{array}{l}731.06 \\
731.19 \\
731.87 \\
732.63 \\
732.72 \\
732.84 \\
732.87 \\
733.52\end{array}$ & $\begin{array}{l}0.6 \\
8.2 \\
8.7 \\
9.9 \\
2.9 \\
4.5 \\
7.6 \\
8.6\end{array}$ & $\begin{array}{l}0.0 \\
0.0 \\
0.0 \\
5.0 \\
0.0 \\
1.9 \\
6.2 \\
0.1\end{array}$ & $\begin{array}{r}5 \\
68 \\
72 \\
41 \\
24 \\
22 \\
11 \\
71\end{array}$ \\
\hline $17-1,146.00$ & 741.46 & 8.3 & 4.2 & 34 \\
\hline $\begin{array}{l}18-1,141.00 \\
18-2,44.00 \\
18-2,131.00 \\
18-3,57.00 \\
18-3,129.00 \\
18-4,79.00 \\
18-4,111.00\end{array}$ & $\begin{array}{l}750.41 \\
750.94 \\
751.81 \\
752.57 \\
753.29 \\
754.29 \\
754.61\end{array}$ & $\begin{array}{l}9.9 \\
1.0 \\
0.2 \\
0.5 \\
3.8 \\
2.1 \\
1.6\end{array}$ & $\begin{array}{l}0.1 \\
0.1 \\
0.0 \\
0.0 \\
0.1 \\
1.0 \\
0.1\end{array}$ & $\begin{array}{r}82 \\
8 \\
1 \\
4 \\
30 \\
10 \\
13\end{array}$ \\
\hline \multicolumn{5}{|l|}{ Site 154} \\
\hline $\begin{array}{l}1-1,74.00 \\
1-2,15.00 \\
1-3,74.00 \\
1-4,76.00 \\
1-5,133.00 \\
1-6,90.00\end{array}$ & $\begin{array}{l}52.74 \\
53.65 \\
55.74 \\
57.26 \\
59.33 \\
60.40\end{array}$ & $\begin{array}{l}2.5 \\
2.8 \\
4.2 \\
4.9 \\
4.8 \\
4.6\end{array}$ & $\begin{array}{l}0.2 \\
0.2 \\
0.1 \\
0.1 \\
0.2 \\
0.1\end{array}$ & $\begin{array}{l}20 \\
22 \\
34 \\
40 \\
38 \\
37\end{array}$ \\
\hline $\begin{array}{l}2-2,109.00 \\
2-3,58.00 \\
2-5,62.00 \\
2-6,18.50 \\
2-7,32.00\end{array}$ & $\begin{array}{l}110.59 \\
111.58 \\
114.62 \\
115.69 \\
117.32\end{array}$ & $\begin{array}{l}3.9 \\
4.3 \\
4.4 \\
4.4 \\
3.0\end{array}$ & $\begin{array}{l}0.2 \\
0.0 \\
0.2 \\
0.2 \\
0.1\end{array}$ & $\begin{array}{l}31 \\
36 \\
35 \\
35 \\
24\end{array}$ \\
\hline $\begin{array}{l}3-2,4.00 \\
3-3,71.00\end{array}$ & $\begin{array}{l}165.54 \\
167.71\end{array}$ & $\begin{array}{l}2.3 \\
0.3\end{array}$ & $\begin{array}{l}0.3 \\
0.1\end{array}$ & $\begin{array}{r}17 \\
1\end{array}$ \\
\hline $\begin{array}{l}4-2,96.00 \\
4-3,9.50\end{array}$ & $\begin{array}{l}175.46 \\
176.09\end{array}$ & $\begin{array}{l}0.1 \\
0.4\end{array}$ & $\begin{array}{l}0.0 \\
0.1\end{array}$ & $\begin{array}{l}1 \\
3\end{array}$ \\
\hline
\end{tabular}

TABLE 1 - Continued

\begin{tabular}{|c|c|c|c|c|}
\hline $\begin{array}{l}\text { Core, Section } \\
\text { Top of } \\
\text { Interval } \\
\text { (cm) }\end{array}$ & $\begin{array}{l}\text { Depth } \\
\text { in Hole } \\
\text { (m) }\end{array}$ & $\begin{array}{c}\text { Carbon } \\
\text { Total } \\
(\%)\end{array}$ & $\begin{array}{c}\text { Organic } \\
\text { Carbon } \\
(\%)\end{array}$ & $\begin{array}{c}\mathrm{CaCO}_{3} \\
(\%)\end{array}$ \\
\hline $\begin{array}{l}5-1,5.00 \\
5-2,71.00 \\
5-3,21.00 \\
5-6,79.00\end{array}$ & $\begin{array}{l}182.05 \\
184.21 \\
185.21 \\
190.29\end{array}$ & $\begin{array}{l}1.6 \\
0.1 \\
1.5 \\
0.1\end{array}$ & $\begin{array}{l}0.3 \\
0.0 \\
0.2 \\
0.0\end{array}$ & $\begin{array}{r}11 \\
1 \\
11 \\
0\end{array}$ \\
\hline $6-1,18.00$ & 192.18 & 0.6 & 0.3 & 2 \\
\hline $\begin{array}{l}8-1,71.50 \\
8-2,111.00 \\
8-3,30.50 \\
8-4,120.00 \\
8-5,110.00 \\
8-6,136.00\end{array}$ & $\begin{array}{l}211.71 \\
213.61 \\
214.30 \\
216.70 \\
218.10 \\
219.86\end{array}$ & $\begin{array}{l}2.8 \\
1.4 \\
2.0 \\
1.1 \\
1.5 \\
3.1\end{array}$ & $\begin{array}{l}1.8 \\
0.9 \\
1.3 \\
0.6 \\
1.0 \\
2.7\end{array}$ & $\begin{array}{l}8 \\
4 \\
6 \\
4 \\
5 \\
5 \\
3\end{array}$ \\
\hline $9-1,109.00$ & 222.09 & 0.1 & 0.0 & 1 \\
\hline $\begin{array}{l}10-1,142.00 \\
10-2,103.00 \\
10-3,20.00\end{array}$ & $\begin{array}{l}231.42 \\
232.53 \\
233.20\end{array}$ & $\begin{array}{l}0.4 \\
0.4 \\
5.4\end{array}$ & $\begin{array}{l}0.2 \\
0.2 \\
3.5\end{array}$ & $\begin{array}{r}2 \\
2 \\
16\end{array}$ \\
\hline $\begin{array}{l}11-1,138.00 \\
11-2,88.00 \\
11-3,60.00\end{array}$ & $\begin{array}{l}241.38 \\
242.38 \\
243.60\end{array}$ & $\begin{array}{l}6.0 \\
0.1 \\
1.4\end{array}$ & $\begin{array}{l}5.9 \\
0.0 \\
0.7\end{array}$ & $\begin{array}{l}1 \\
0 \\
6\end{array}$ \\
\hline $\begin{array}{l}12-1,75.00 \\
12-2,146.00\end{array}$ & $\begin{array}{l}249.75 \\
251.96\end{array}$ & $\begin{array}{l}0.6 \\
0.8\end{array}$ & $\begin{array}{l}0.2 \\
0.4\end{array}$ & $\begin{array}{l}3 \\
4\end{array}$ \\
\hline $\begin{array}{l}13-1,124.00 \\
13-3,50.00 \\
13-5,127.00 \\
13-6,74.00\end{array}$ & $\begin{array}{l}259.24 \\
261.50 \\
265.27 \\
266.24\end{array}$ & $\begin{array}{l}2.6 \\
0.2 \\
0.2 \\
0.2\end{array}$ & $\begin{array}{l}1.5 \\
0.1 \\
0.1 \\
0.1\end{array}$ & $\begin{array}{l}9 \\
1 \\
1 \\
1\end{array}$ \\
\hline $14-1,50.00$ & 268.50 & 0.1 & 0.0 & 0 \\
\hline
\end{tabular}

Site 154A

\begin{tabular}{lcccl}
$1-1,100.00$ & 2.00 & 2.8 & 0.1 & 23 \\
$1-2,23.00$ & 2.73 & 2.8 & 0.2 & 22 \\
$1-3,26.00$ & 4.26 & 4.2 & 0.2 & 34 \\
$1-4,136.00$ & 6.86 & 4.5 & 0.2 & 35 \\
$1-5,71.50$ & 7.71 & 3.6 & 0.1 & 29 \\
$2-2,12.50$ & 11.63 & 3.2 & 0.2 & 25 \\
$2-3,11.00$ & 13.11 & 3.4 & 0.2 & 27 \\
$3-1,100.00$ & 21.00 & 4.3 & 0.2 & 34 \\
$3-2,11.50$ & 21.62 & 4.4 & 0.2 & 35 \\
$3-3,11.50$ & 23.12 & 3.5 & 0.2 & 28 \\
$3-4,11.50$ & 24.62 & 2.5 & 0.2 & 19 \\
$3-5,5.00$ & 26.05 & 3.6 & 0.1 & 29 \\
$3-6,123.00$ & 28.73 & 4.6 & 0.1 & 37 \\
$4-1,6.50$ & 29.06 & 3.2 & 0.2 & 25 \\
$4-2,93.00$ & 31.43 & 2.9 & 0.2 & 23 \\
$4-3,10.00$ & 32.10 & 2.5 & 0.1 & 20 \\
$4-4,6.00$ & 33.56 & 3.8 & 0.2 & 31 \\
$4-5,86.50$ & 35.87 & 3.4 & 0.2 & 27 \\
$4-6,17.00$ & 36.67 & 4.1 & 0.1 & 33 \\
$5-2,99.00$ & 41.49 & 2.9 & 0.2 & 23 \\
$6-2,0.00$ & 50.50 & 3.9 & 0.2 & 31 \\
$6-3,0.00$ & 52.00 & 3.8 & 0.2 & 31 \\
$6-4,0.00$ & 53.50 & 3.3 & 0.2 & 26 \\
$6-6,0.00$ & 56.50 & 3.7 & 0.2 & 30 \\
$7-1,112.00$ & 60.12 & 3.8 & 0.2 & 30 \\
$7-2,72.00$ & 61.22 & 3.9 & 0.1 & 31 \\
$8-1,132.00$ & 69.32 & 3.9 & 0.2 & 31 \\
$8-2,17.00$ & 69.67 & 3.9 & 0.1 & 31 \\
$8-3,40.00$ & 71.40 & 4.7 & 0.1 & 38 \\
$8-4,20.00$ & 72.70 & 3.5 & 0.2 & 28 \\
$8-5,74.00$ & 74.74 & 3.5 & 0.1 & 28 \\
$8-6,130.00$ & 76.80 & 5.0 & 0.1 & 41 \\
\hline & & & & \\
\hline
\end{tabular}


TABLE 1 - Continued

\begin{tabular}{|c|c|c|c|c|}
\hline $\begin{array}{l}\text { Core, Section } \\
\text { Top of } \\
\text { Interval } \\
\text { (cm) }\end{array}$ & $\begin{array}{l}\text { Depth } \\
\text { in Hole } \\
(\mathrm{m})\end{array}$ & $\begin{array}{c}\text { Carbon } \\
\text { Total } \\
(\%)\end{array}$ & $\begin{array}{c}\text { Organic } \\
\text { Carbon } \\
(\%)\end{array}$ & $\begin{array}{c}\mathrm{CaCO}_{3} \\
(\%)\end{array}$ \\
\hline $\begin{array}{l}9-1,90.00 \\
9-1,101.00 \\
9-2,100.00 \\
9-3,119.00 \\
9-4,65.00 \\
9-5,76.00 \\
9-6,58.00\end{array}$ & $\begin{array}{l}78.90 \\
79.01 \\
80.50 \\
82.19 \\
83.15 \\
84.76 \\
86.08\end{array}$ & $\begin{array}{l}4.9 \\
4.3 \\
4.7 \\
5.2 \\
4.2 \\
4.2 \\
4.5\end{array}$ & $\begin{array}{l}0.1 \\
0.1 \\
0.1 \\
0.1 \\
0.1 \\
0.1 \\
0.1\end{array}$ & $\begin{array}{l}40 \\
35 \\
38 \\
43 \\
34 \\
34 \\
37\end{array}$ \\
\hline $\begin{array}{l}10-1,97.00 \\
10-2,92.00 \\
10-3,29.00 \\
10-4,127.00 \\
10-5,62.00 \\
10-6,119.00\end{array}$ & $\begin{array}{l}87.97 \\
89.42 \\
90.29 \\
92.77 \\
93.62 \\
95.69\end{array}$ & $\begin{array}{l}5.3 \\
5.9 \\
5.1 \\
4.3 \\
4.0 \\
3.5\end{array}$ & $\begin{array}{l}0.1 \\
0.1 \\
0.1 \\
0.2 \\
0.1 \\
0.2\end{array}$ & $\begin{array}{l}43 \\
48 \\
42 \\
34 \\
32 \\
27\end{array}$ \\
\hline $\begin{array}{l}11-2,88.00 \\
11-3,65.00 \\
11-4,137.00 \\
11-5,113.00 \\
11-6,134.00\end{array}$ & $\begin{array}{r}99.38 \\
100.65 \\
102.87 \\
104.13 \\
105.84\end{array}$ & $\begin{array}{l}4.2 \\
3.5 \\
4.2 \\
4.7 \\
4.9\end{array}$ & $\begin{array}{l}0.2 \\
0.2 \\
0.1 \\
0.2 \\
0.2\end{array}$ & $\begin{array}{l}33 \\
28 \\
34 \\
38 \\
39\end{array}$ \\
\hline $\begin{array}{l}12-1,110.00 \\
12-2,134.00 \\
12-3,134.00 \\
12-5,39.00 \\
12-6,121.00\end{array}$ & $\begin{array}{l}107.10 \\
108.84 \\
110.34 \\
112.39 \\
114.71\end{array}$ & $\begin{array}{l}4.4 \\
4.7 \\
3.9 \\
4.5 \\
4.1\end{array}$ & $\begin{array}{l}0.1 \\
0.1 \\
0.2 \\
0.1 \\
0.2\end{array}$ & $\begin{array}{l}36 \\
38 \\
31 \\
36 \\
32\end{array}$ \\
\hline $\begin{array}{l}13-1,142.00 \\
13-2,24.00 \\
13-3,130.00 \\
13-4,56.00 \\
13-5,119.00\end{array}$ & $\begin{array}{l}117.42 \\
117.74 \\
120.30 \\
121.06 \\
123.19\end{array}$ & $\begin{array}{l}4.0 \\
3.5 \\
4.9 \\
4.7 \\
3.7\end{array}$ & $\begin{array}{l}0.2 \\
0.1 \\
0.1 \\
0.1 \\
0.2\end{array}$ & $\begin{array}{l}32 \\
28 \\
40 \\
38 \\
29\end{array}$ \\
\hline
\end{tabular}

TABLE 1 - Continued

\begin{tabular}{lcccc}
\hline $\begin{array}{c}\text { Core, Section } \\
\text { Top of } \\
\text { Interval } \\
\text { (cm) }\end{array}$ & $\begin{array}{c}\text { Depth } \\
\text { in Holc } \\
(\mathrm{m})\end{array}$ & $\begin{array}{c}\text { Carbon } \\
\text { Total } \\
(\%)\end{array}$ & $\begin{array}{c}\text { Organic } \\
\text { Carbon } \\
(\%)\end{array}$ & $\begin{array}{c}\mathrm{CaCO}_{3} \\
(\%)\end{array}$ \\
\hline $13-6,136.00$ & 124.86 & 3.3 & 0.2 & 26 \\
$14-1,115.00$ & 126.15 & 4.3 & 0.2 & 34 \\
$14-2,57.00$ & 127.07 & 3.3 & 0.2 & 26 \\
$14-3,91.00$ & 128.91 & 3.9 & 0.2 & 31 \\
$14-4,16.00$ & 129.66 & 3.1 & 0.2 & 24 \\
$14-5,18.00$ & 131.18 & 1.7 & 0.2 & 13 \\
$14-6,30.00$ & 132.80 & 3.1 & 0.2 & 24 \\
$15-2,6.00$ & 135.56 & 2.4 & 0.3 & 17 \\
$15-3,15.00$ & 137.15 & 2.9 & 0.3 & 22 \\
$15-4,8.00$ & 138.58 & 0.9 & 0.2 & 5 \\
$15-5,62.00$ & 140.62 & 2.1 & 0.4 & 15 \\
$16-1,8.00$ & 144.08 & 3.7 & 0.3 & 29 \\
$16-2,49.00$ & 145.99 & 0.7 & 0.3 & 4 \\
$16-3,12.00$ & 147.12 & 1.5 & 0.4 & 9 \\
$16-4,13.00$ & 148.63 & 1.5 & 0.3 & 10 \\
$16-5,22.00$ & 150.22 & 0.5 & 0.3 & 1 \\
$16-6,13.00$ & 151.63 & 2.6 & 0.4 & 18 \\
$17-1,51.00$ & 153.51 & 1.4 & 0.4 & 8 \\
$17-3,13.00$ & 156.13 & 0.4 & 0.2 & 2 \\
$17-4,105.00$ & 158.55 & 0.2 & 0.1 & 1 \\
$17-5,45.00$ & 159.45 & 0.1 & 0.0 & 0 \\
$17-6,99.00$ & 161.49 & 0.2 & 0.1 & 1 \\
$18-2,28.00$ & 164.78 & 0.0 & 0.0 & 0 \\
$18-3,39.00$ & 166.39 & 0.3 & 0.2 & 1 \\
$18-4,33.00$ & 167.83 & 0.4 & 0.2 & 2 \\
& & & &
\end{tabular}

*Samples analyzed using Acid-Base method. See text. 